\title{
Notch effect and fracture load predictions of rock beams at different temperatures using the Theory of Critical Distances
}

\author{
J. Justo ${ }^{a *}$, J. Castro ${ }^{a}$, S. Cicero ${ }^{b}$ \\ ${ }^{a}$ Group of Geotechnical Engineering, Universidad de Cantabria, E.T.S de Ingenieros de Caminos, Canales y Puertos, Av/ \\ Los Castros 44, 39005, Santander, Spain

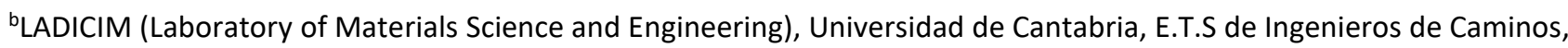 \\ Canales y Puertos, Av/ Los Castros 44, 39005, Santander, Spain \\ * Contact person: justoj@unican.es
}

\begin{abstract}
This work aims to analyse the fracture behaviour of rocks with U-shaped notches subjected to mode I loading and to different temperature conditions. To this end, the so called Theory of Critical Distances (TCD) is applied and four different types of isotropic rocks are studied: a Floresta sandstone, a Moleano limestone, a Macael marble and a Carrara marble. This study attempts to extend a previous work of the authors where the TCD was successfully applied to U-notched components subjected to mode I loading conditions at room temperature. In this case, the effect of temperature is considered as a new variable.
\end{abstract}

The research comprises, in total, more than 790 four-point bending tests and 144 tensile splitting (Brazilian) tests. The latter include 6 disc-shaped specimens for each rock and temperature (6 different temperatures), while the four-point bending tests consist of at least 6 SENB specimens for each rock, notch radius ( 8 different notch radii varying from $0.15 \mathrm{~mm}$ to $15 \mathrm{~mm}$ ) and temperature (4 different temperatures) combination. The temperatures considered in this study vary from room temperature up to $250 \circ \mathrm{C}$, which is a common range in geothermal applications.

Temperature has proven to be a significant parameter when analysing the fracture behaviour of the four selected rocks. Its influence on the tensile strength and fracture toughness of the rocks is clear and reveals common patterns. However, no apparent tendencies are shown on the influence of temperature on the critical distance $(L)$. Likewise, the application of the TCD has led to relatively accurate fracture predictions and notch effect analyses at different temperature conditions.

KEYWORDS: Theory of Critical Distances; temperature; notch; rock; marble; sandstone; limestone.

\section{INTRODUCTION}

The different geological processes that rocks have undergone over millennia have endowed them with a strong heterogeneous component both at macro- and micro-scales. Although the rock matrix may 
sometimes emerge healthy in nature, the presence of defects with different scales is irremediable from an integrity point of view. The existence of different elements such as pores, grain boundaries, discontinuities, joints, holes, cracks, microcracks or notches define the mechanical behaviour of rocks, no matter whether they are naturally in the rock or man-made. All these elements can be considered as stress risers and play a key role during the fracture initiation processes. However, there are different fracture approaches depending on the kind of stress riser that is being analysed. In this sense, notch-type defects develop a higher load-bearing capacity than crack-type defects, since they generate less demanding stress fields around them. Many studies can be found in the literature dealing with the stress field in the notch tip,,$^{1-3}$ and all of them suggest a reduction of the stress acting perpendicular to the notch plane. Basically, linear fracture mechanics addresses crack problems or ideally sharp notch problems where the notch radius can be assumed to be equal to zero $(\rho=0)$. However, from a strict point of view, every notch has a finite radius and proceeding on the assumption that notches behave like sharp cracks (as considered by traditional fracture mechanics) may be overly conservative in many cases. Thus, it is important to distinguish between cracks and notches when evaluating the fracture of rock masses.

Different notches with different geometries, sizes and shapes are often created artificially in large rock masses, as for example for the construction of dams, tunnels, mining excavations, gas and oil wells, etc., which can be generally studied as V-shaped or U-shaped notches, or even as intermediate situations like rounded V-notches. For this reason, the influence of the notch geometry (i.e., radius, shape, opening angle and other geometrical aspects) on the fracture behaviour of different components has been widely studied by many authors (e.g. $\left.{ }^{4-6}\right)$.

The study of the rock fracture behaviour, from an experimental perspective, is subjected to continuous development. Indeed, even though some authors express certain preferences, none of the existing methodologies for conducting mode I or mixed mode fracture of rocks stands out among the rest. Many testing methods and specimen shapes and configurations have been analysed in this regard, such as SCB (e.g.7), CCCD (e.g.7), ECT (e.g.8), ENDB (e.g.9) or SVR (e.g.10), among many others. Although the exact value of the fracture toughness may slightly depend on the size shape and type of the specimen (e.g. $\left.{ }^{11}\right)$, here the focus is on the variation of the apparent fracture toughness with the notch radius and temperature. Single Edge Notch Bend (SENB) specimens have been studied, subjected to four-point bending conditions and with different $U$-shaped notches varying from $0.15 \mathrm{~mm}$ to $15 \mathrm{~mm}$ radii. This test configuration guarantees constant bending moment and no shear forces between the two loading points. Thus, Mode I loading conditions are fulfilled.

Dealing with the fracture analysis of notched components, different criteria can be found in the literature based on global or local approaches. The global fracture criterion states that fracture will occur 
when the notch stress intensity factor $\left(K_{\rho}\right)$ reaches a critical value $\left(K_{\rho}^{c}\right)$ that only depends on the material and on the notch radius $(\rho)$. This approach is analogous to the one proposed by traditional linear-elastic fracture mechanics for cracked components where the fracture criterion is defined by $K_{I}=K_{I C}$, $K_{I}$ being the stress intensity factor in a cracked component and $K_{I C}$ being the (plane strain) fracture toughness of the material. By contrast, local fracture criteria are based on the stress-strain field at the notch tip. They may use values of a given variable (e.g., stress, strain energy, etc) at a particular point (e.g. ${ }^{12}$ ) or values along a certain line or a surrounding volume (e.g. $\left.{ }^{13}\right)$.

Many fracture criteria have been proposed in fracture mechanics for predicting the onset of failure of notches samples: Gomez et al. ${ }^{14}$ worked on a criterion for brittle and quasi-brittle materials under monotonic loading, based on the Cohesive Zone Model (CZM) proposed in the past by Dugdale ${ }^{15}$ and Barenblatt ${ }^{16}$ to describe stress fields and fracture processes near the defect tip. The CZM has demonstrated to offer good fracture load predictions of notched specimens. ${ }^{14,17}$ The Finite Fracture Mechanics (FFM) criterion is based on the assumption that the crack grows by finite steps, which are determined by a condition of consistency of both energy and stress requirements. ${ }^{18}$ Likewise, the Strain Energy Density (SED) criterion is an energy-based approach that combines the elementary volume proposed by Neuber ${ }^{19}$ and the local Mode I concept first proposed by Erdogan and Sih. ${ }^{20}$ Several publications can also be found on the application of the SED criterion for investigating the fracture behaviour of cracked and notched elements. ${ }^{21-}$ ${ }^{22}$ On the other hand, Taylor ${ }^{23}$ collects the Critical Distance methodologies based on the use of a material characteristic parameter called the critical distance $(L)$. The Theory of Critical Distances (TCD) was first used by Neuber ${ }^{19}$ and Peterson ${ }^{24}$, but it has been in the last years that this theory has been scientifically analysed more in detail. ${ }^{23,25}$ One of the greatest advantages of the TCD consists of the possibility to get (semi-) analytical results without the loss of accuracy, ${ }^{26}$ and without the necessity of computational efforts, as commonly done by the SED criterion or the CZM, for instance. Some other fracture criteria such as the Maximum Tangential Stress (MTS) ${ }^{20}$ criterion, the Maximum Tangential Strain (MTSN) ${ }^{27}$ criterion or the maximum energy release rate $(\mathrm{G})^{28}$ criterion are also widely used.

All the aforementioned criteria have been extensively applied for the fracture assessment of different materials under varied loading and failure conditions. However, the fracture analyses of notched components in the particular field of rock fracture mechanics are scarce and relatively recent. Aliha et al., ${ }^{29}$ for example, provided good predictions of the mode I and II fracture toughness and angle of fracture initiation of a marble using the generalized MTS criterion, considering the effect of the T-stress. Similarly, Mirsayar et al. ${ }^{30}$ used an extended version of the MTSN to study the brittle fracture of two different marbles under mixed mode I/II. This criterion takes into account the first nonsingular strain term and the singular strain components. On the other hand, Aliha et al. ${ }^{31}$ and Razavi et al. ${ }^{32}$ worked on the application of an average SED criterion on the fracture behaviour of a marble and a granite, respectively. The authors have 
also applied the SED criterion to rocks at room temperature in a previous work, ${ }^{13}$ providing good fracture predictions in all the cases.

Here, the TCD will be used for the fracture assessment of 4 types of rocks with different characteristics and lithology. Despite its simplicity and the good results shown in the fracture assessment of structural components made of different materials, little work can be found in the literature on the application of the TCD in rocks (e.g. $\left.{ }^{33-34}\right)$, none of them considering the influence of the temperature on their fracture behaviour.

Temperature has a direct effect on the fracture resistance of any material in general, and of rocks in particular (e.g. ${ }^{35-38}$ ). Being able to predict rock fracture under thermal influence is crucial in many underground engineering fields where its effect is no longer negligible (e.g., geothermal extractions, oil-gas exploitations, hydraulic fracturing). Consequently, a comprehensive description of the variation with temperature of the key parameters that define the fracture processes is important for a better understanding of the mechanical behaviour of rocks. Many authors have already studied the influence of temperature on the fracture behaviour of different rocks, such as sandstones ${ }^{36,39}$ or granites ${ }^{38,40}$, for example. Not only the effect of temperature, ${ }^{36-38}$ but also the effect of thermal treatment ${ }^{35}$ is usually analysed due to the damaging impact of thermal cycles.

The critical distance $(L)$ depends on both the tensile strength $\left(\sigma_{u}\right)$ and the fracture toughness $\left(K_{I C}\right)$ of the analysed rocks, which are certainly affected by the temperature as demonstrated by many authors (e.g., ${ }^{39-}$ ${ }^{43}$ ). For instance, Sirdesai et al. ${ }^{39}$ analysed the effect of temperature and the effect of thermal cycles on the tensile strength of a sandstone, and concluded that the change in the preexisting pores and microcracks caused by the expansion of minerals with temperature results in a change in the tensile strength. Similarly, Dongming and Yushun ${ }^{43}$ analysed the effect of high temperature on the tensile strength of a limestone, where an initial increment followed by a decrease of the tensile strength was observed when temperature increased. Likewise, the fracture toughness reflects the residual strength of a cracked component to crack propagation, and its value is also significantly influenced by the temperature conditions. Several studies can be found in the literature about the thermal influence on the fracture toughness of rocks. ${ }^{40-42}$ In some cases, a reduction in the fracture toughness of rocks has been reported, ${ }^{40}$ caused by the development of microcracks induced by differential thermal expansions between adjacent mineral particles. By contrast, other studies indicate an increase in the fracture toughness up to a certain temperature, mainly due to the closure of microcracks or pores caused by the thermal expansion, ${ }^{41}$ but also because of the heat-induced pore pressure changes. ${ }^{42}$

With all this, new accurate tools should be developed and validated for rock fracture assessment considering the possible notch effect. For this reason, this study will be focussed on notched rock 
components subjected to mode I loading conditions, and will take as a basis a previous work of the authors ${ }^{12}$, where the TCD was successfully applied for the fracture assessment of several isotropic rocks at room temperature. Therefore, this work aims to extend the previous study introducing the temperature as a new variable. To this end, the so called TCD will be used again for the rock fracture assessment, considering this time the thermal effect on the required key parameters up to 250 으, which is a common range of temperatures in geothermal applications.

Subsequently, Section 2 provides a brief theoretical background on the considered fracture criterion in this study (the TCD). Section 3 includes the main aspects related to the experimental program, describing both the analysed materials and the performed tests. All the results dealing with the influence of temperature on the decisive parameters (tensile strength, fracture toughness, critical distance), the notch effect analyses and the fracture predictions will be shown and discussed in Section 4. Finally, Section 5 comprises the conclusions of the research.

\section{THEORETICAL BACKGROUND: THE THEORY OF THE CRITICAL DISTANCES (TCD)}

The TCD comprises a group of methods characterised by the use of the previously mentioned critical distance $(L)$, together with the material fracture toughness $\left(K_{I C}\right)$, and by the fact that they all allow the use of elastic continuum mechanics approaches. ${ }^{23}$ The expression for the critical distance $L$ is as follows:

$L=\frac{1}{\pi}\left(\frac{K_{I C}}{\sigma_{0}}\right)^{2}$

where $\sigma_{0}$ is the inherent strength of the material. In the case of rocks or other quasi-brittle materials, the inherent strength can be assumed to roughly coincide with the tensile strength $\left(\sigma_{u}\right)$ of the material. ${ }^{23}$

The critical distance $(L)$ is somehow related to the microstructural properties and to what is broadly referred to as the Fracture Process Zone (FPZ). This process zone is developed in rocks as a consequence of the initiation and coalescence of microcracks in front of the defect tip when increasing the applied load level.

According to Taylor, ${ }^{23}$ all the methods included within the TCD offer reasonably similar predictions. Thus, among all these methods, those with a more straightforward application will be used in this work: the Point Method (PM) and the Line Method (LM). The former states that failure occurs when the stress at a certain distance $\left(r_{c}\right)$ from the notch tip reaches the inherent stress $\left(\sigma_{0}\right)$. This distance $r_{c}$ is related to the FPZ according to the maximum principle stress model suggested by Schmidt, ${ }^{44}$ and is equivalent to the critical distance divided by two $\left(r_{c}=L / 2\right)$. Therefore, the failure criterion is defined by the following expression in the case of the PM: 
$\sigma(L / 2)=\sigma_{0}$

Proceeding along similar tracks, the LM defines the failure criterion as the situation where the average stress over a distance $d$ starting at the defect tip is equal to the inherent strength $\left(\sigma_{0}\right)$ (see Eq. (3)). It can be analytically demonstrated from the stress field at the defect tip and from the definition of $L$ from Eq. (1) that the distance $d$ is equal to two times the critical distance $(d=2 L) \cdot{ }^{23}$

$\frac{1}{2 L} \int_{0}^{2 L} \sigma(r) d r=\sigma_{0}$

This research uses both the PM and the LM for the assessment of U-shaped notched components. To this end, their fracture analysis is equated to a situation in a cracked component where the apparent fracture toughness $\left(K_{I N}\right)$ is considered instead of the real fracture toughness $\left(K_{I C}\right)$. Thus, fracture will occur when the following equation is fulfilled:

$K_{I}=K_{I N}$

where $K_{I}$ is the stress intensity factor (SIF) for a crack with the same length as the notch. From a strict point of view, the real fracture toughness $\left(K_{I C}\right)$ corresponds to a cracked situation in which the notch radius is equal to zero $(\rho=0)$. However, unlike metallic materials, introducing a crack into a rock with a controlled length is not possible due to their brittle condition that makes the crack unstable. Instead, crack-like defects might be introduced into the rocks by means of a sharp slot machined into the specimen. According to Taylor, ${ }^{23}$ even if the introduced slot has a finite radius different from zero, as long as the radius is smaller than the critical distance of the analysed material it will behave as a crack rather than a notch. By contrast, when the notch radius is larger than the critical distance $L$, the notch effect will no longer be negligible. As demonstrated by the authors, ${ }^{12}$ the critical distance $L$ of the studied rocks is of the order of a few millimetres. For this reason, the smallest performed notches $(\rho=0.15 \mathrm{~mm})$ will be considered as crack-type defects, assuming that $K_{I N}=K_{I C}$ in this case.

Both the PM and the LM provide expressions for the calculation of the apparent fracture toughness $\left(K_{I N}\right)$. These expressions are analytically obtained and are based on the stress distribution proposed by Creager and Paris ${ }^{1}$ as a function of the stress intensity factor $\left(K_{I}\right)$, the distance $(r)$ from the notch tip, and the notch radius $(\rho)$ :

$\sigma(r)=\frac{K_{I}}{\sqrt{\pi}} \frac{2(r+\rho)}{(2 r+\rho)^{3 / 2}}$

Considering the PM criterion (Eq. (2)), and establishing the failure criterion defined by Eq. (4), Eq. (5) can be rewritten as follows: 
$K_{I N}=\sigma_{0} \sqrt{\pi}\left[\frac{\sqrt{(L+\rho)^{3}}}{L+2 \rho}\right]$

Finally, combining Eq. (6) with the definition of $L$ shown above (Eq. (1)), the analytical solution for the PM corresponds to the following expression:

$K_{I N}=K_{I C} \frac{\left(1+\frac{\rho}{L}\right)^{3 / 2}}{\left(1+\frac{2 \rho}{L}\right)}$

Analogously, considering the LM criterion (Eq. (3)) and the stress field proposed in Eq. (5), the following solution is obtained:

$K_{I N}=K_{I C} \sqrt{\frac{\rho}{4 L}+1}$

Both Eq. (7) and Eq. (8) offer similar and reliable solutions as long as semi-infinite body dimensions are considered. ${ }^{23}$ Besides, Eq. (5) is theoretically only valid for long and narrow notches.

\section{EXPERIMENTAL PROGRAM}

\subsection{ANALYSED ROCKS}

Four different types of rocks are analysed in this article: a Floresta sandstone (F), a Moleano limestone (C), a Macael marble (M) and a Carrara marble (I). They all have different characteristics from a microstructural point of view in an attempt to cover a broad casuistic and therefore prove the suitability of the TCD in rock fracture assessment. The selected rocks are all isotropic and were previously analysed by the authors at room temperature, ${ }^{12}$ providing a description of their microstructure. Some of their most relevant technical properties are summarised in Table 1.

Table 1.- Some technical properties of each material. F: Floresta sandstone; C: Moleano limestone; M: Macael marble; I: Carrara Marble.

\begin{tabular}{lcccc}
\hline & $(\mathrm{F})$ & $(\mathrm{C})$ & $(\mathrm{M})$ & $(\mathbf{I})$ \\
\hline Bulk density $\left(\mathbf{k g} / \mathbf{m}^{\mathbf{3}}\right)$ & 2320 & 2500 & 2715 & 2709 \\
Open porosity $(\%)$ & 16.3 & 6.4 & - & - \\
Water absorption $(\%)$ & 4.80 & 2.70 & 0.075 & 0.15 \\
Mean grain size $(\boldsymbol{\mu m})$ & 116 & 218 & 335 & 142 \\
Median grain size $(\boldsymbol{\mu m})$ & 109 & 183 & 282 & 131 \\
\hline
\end{tabular}

\subsection{TESTING CAMPAIGN}

A correct definition of the tensile strength $\left(\sigma_{u}\right)$ is very important for the correct application of the TCD. For this reason, 6 splitting tensile strength tests (Brazilian tests) were performed for each rock and 
temperature, considering room temperature (approximately $23^{\circ} \mathrm{C}$ ), $70^{\circ} \mathrm{C}, 110^{\circ} \mathrm{C}, 150^{\circ} \mathrm{C}, 200^{\circ} \mathrm{C}$ and $250^{\circ} \mathrm{C}$. Fig. 1a shows experimental setup during the Brazilian tests, where curved platens were used to apply the load. All these tests were executed using $64 \mathrm{~mm}$ diameter disk specimens and according to the Spanish standards, ${ }^{45}$ which are similar to those established by the ASTM. ${ }^{46}$
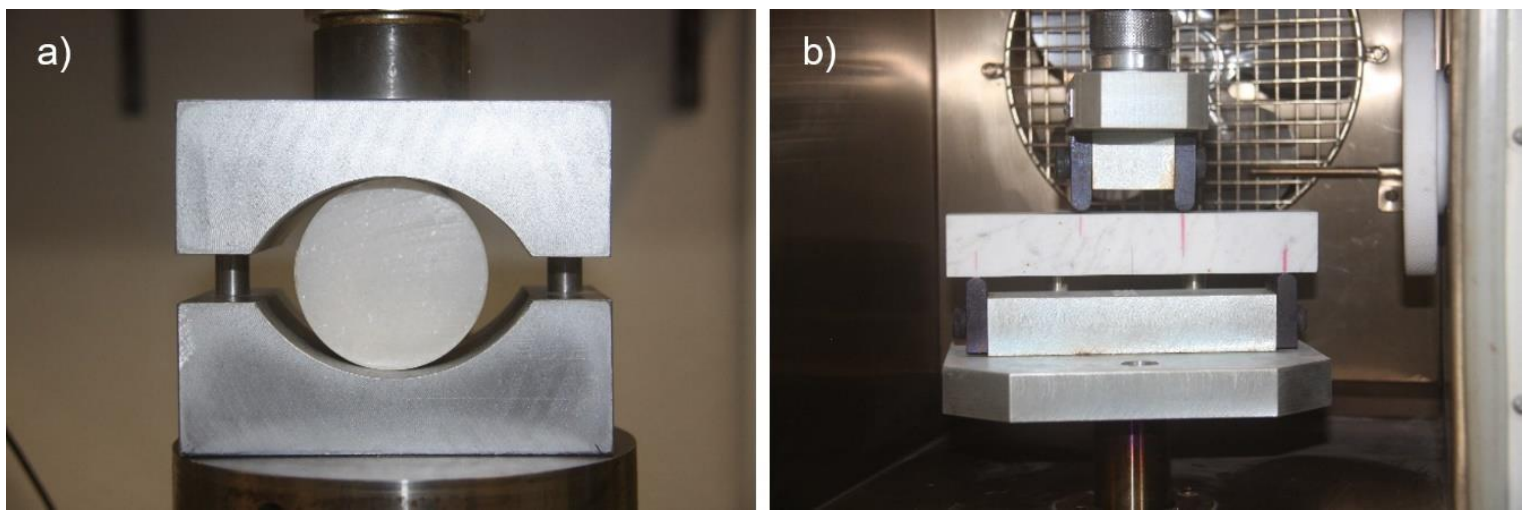

Fig. 1.- Experimental setup of the Brazilian tests (a) and four-point bending tests (b).

Likewise, many experimental methods can be found in the literature to test the fracture toughness of geomaterials like rocks using specimens with different geometries. Among all the methodologies collected by Amaral et al. ${ }^{47}$ for the fracture toughness assessment of rocks, the four-point bending method has been

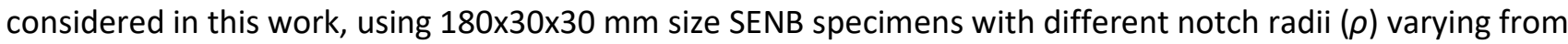
$0.15 \mathrm{~mm}$ up to $15 \mathrm{~mm}$. A picture of the experimental setup is shown in Fig. $1 \mathrm{~b}$ and a more detailed scheme with the geometrical aspects is represented in Fig. 2. These tests were performed following the Spanish ${ }^{48}$ and European ${ }^{49}$ standards, with a constant loading rate of $0.05 \mathrm{~mm} / \mathrm{min}$ till failure. More details on the experimental setup are provided by the authors in a previous work. ${ }^{12}$

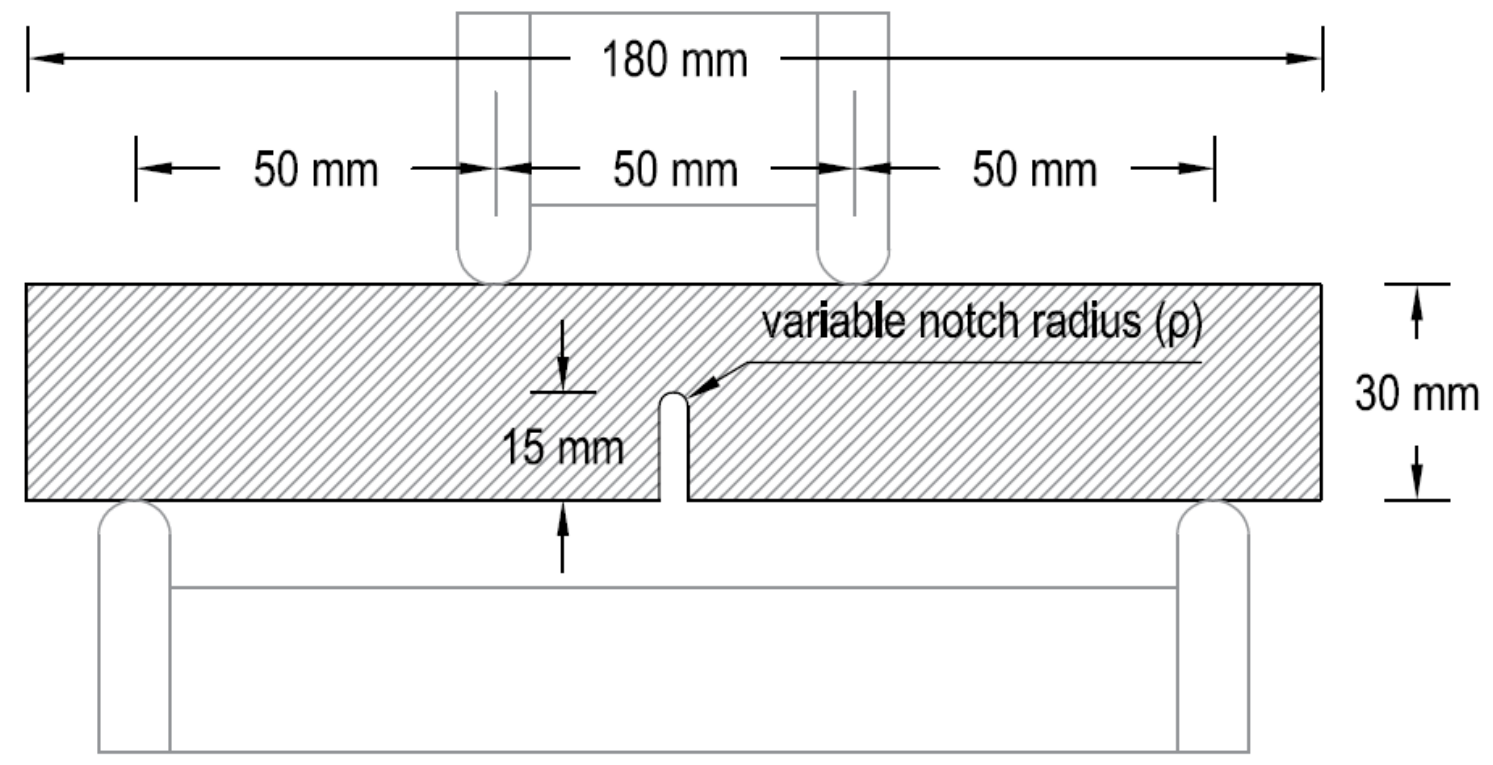

Fig. 2.- Schematic representation of the four-point bending tests. 
Both the Brazilian testing device and the four-point bending apparatus were placed inside an oven that was previously coupled to the press. The steel rod transferring the loads from the press to the testing devices inside the oven was provided with a spherical joint that allows a greater degree of adjustment while ensuring that the axis of load application remains centred. This experimental setup guarantees constant temperature conditions throughout the duration of the tests. Besides, all the specimens were preheated to the target temperature for at least 48 hours before testing, which ensures a constant and homogeneous temperature of the sample according to Newton's heating law.

According to the CEN/TS $14425-1{ }^{49}$ the following formulation is used for the calculation of the fracture toughness values $\left(K_{I C}\right)$ of SENB specimens, which was first proposed by Srawley and Gross: ${ }^{50}$

$K_{I C}=\frac{F \cdot Y}{b \cdot h^{1 / 2}}$

where $F$ is the obtained failure load during the four-point bending tests, $b$ and $h$ are the specimen depth and height, respectively, and $Y$ is the compliance factor given by the following expression:

$Y=\frac{3 \cdot\left(L_{0}-L_{i}\right) \cdot \alpha_{0}^{1 / 2} \cdot X}{2 h \cdot\left(1-\alpha_{0}\right)^{3 / 2}}$

with

$X=1.9887-\left[\frac{\left(3.49-0.68 \alpha_{0}-1.35 \alpha_{0}^{2}\right) \cdot \alpha_{0} \cdot\left(1-\alpha_{0}\right)}{\left(1+\alpha_{0}\right)^{2}}\right]-1.32 \alpha_{0}$

$L_{o}$ and $L_{i}$ are, respectively, the spans between the outer supporting rollers and the inner loading points as depicted in Fig. 2. On the other hand, $\alpha_{0}$ refers to the relative crack length, defined as the ratio between the initial crack length $\left(a_{0}\right)$ and the total height of the specimen $(h)$. The small variations in the initial notch length and total height of the prepared specimens are due to the precision of the cutting process. However, high confinement conditions are always guaranteed ( $\left.0.45 \leq \alpha_{0}=a_{0} / h \leq 0.55\right)$.

All in all, more than 790 four-point bending tests have been performed, at least 6 for each rock, notch radius and temperature combination. 4 different temperatures have been considered in this case: $23 \circ \mathrm{C}$, $70^{\circ} \mathrm{C}, 150^{\circ} \mathrm{C}$ and $250^{\circ} \mathrm{C}$. Likewise, 8 different notch radii have been studied: $0.15,0.5,1,2,4,7,10$ and 15 $\mathrm{mm}$, as those shown in Fig. 3. As mentioned above, those notches with $\rho=0.15 \mathrm{~mm}$ can be assumed to behave as crack-type defects despite their finite radius, providing a reasonable approximation to the real fracture toughness $\left(K_{I C}\right)$ from Eq. (9). Conversely, the rest of notches may provide an apparent fracture toughness $\left(K_{I N}\right)$ higher than $K_{I C}$. The largest notch radius is conditioned by the height of the specimen, which, in order to maintain the relative crack length in the defined range, cannot be greater than $15 \mathrm{~mm}$. Those notches with a radius larger than $1 \mathrm{~mm}$ were manufactured using abrasive discs with semi-circular 
contour, and the smallest radii, those with 0.15 and $0.5 \mathrm{~mm}$, were executed using rotating diamond wires. In any case, both methods provide U-shaped notches.

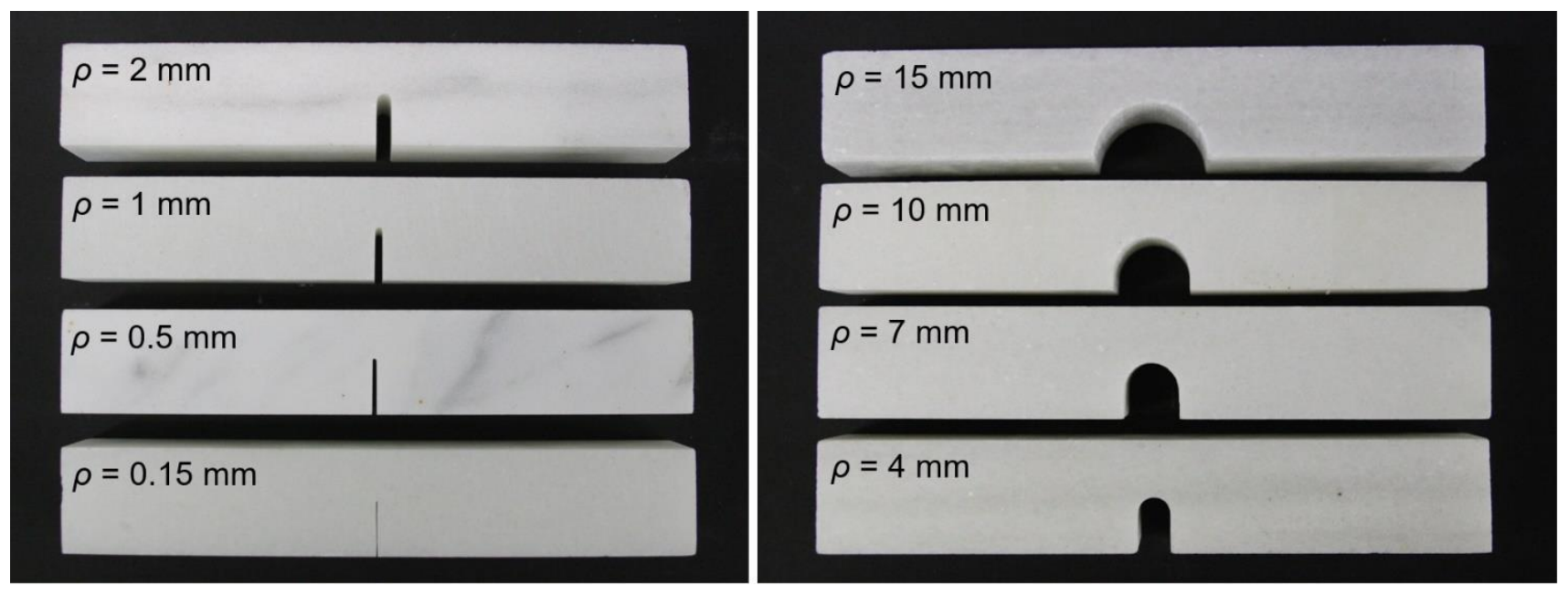

Fig. 3.- SENB samples with different notch radii.

\section{RESULTS AND DISCUSSION}

Both the TCD and the considered experimental procedures are based on the assumption that rocks behave as brittle materials at the studied range of temperatures. However, although the TCD is based on Linear Elastic Fracture Mechanics (LEFM), it can also be applied for non-perfectly linear analyses by calibrating the value of the critical distance $(L)$. In this case the value of the inherent strength $\left(\sigma_{0}\right)$ would be different to $\sigma_{u}{ }^{23}$

In order to verify that no significant inelastic deformations are produced and that the use of LEFM is valid up to $250^{\circ} \mathrm{C}$ the load-displacement curves of the four-point bending tests have been analysed in Figure 4. Each column corresponds to a different rock and, for the sake of simplicity, only some representative results of the specimens with $0.15 \mathrm{~mm}$ and $15 \mathrm{~mm}$ notch radii have been included in the first and second row, respectively. The solid curves stand for the room temperature case, while the dashed lines correspond to $250^{\circ} \mathrm{C}$. The initial non-linear part of the curves is bounded to the test procedure, caused by the initial adjustment of the testing device on the specimen. Thus, it should be ignored in terms of deformations, but not in terms of load.

The influence of temperature and the notch radius on the strength of the rocks is discussed in the following sections. However, observing the linearity of the curves prior to the peaks, the brittle characteristics of the Floresta sandstone (F) and the Moleano limestone (C) are obvious even at high temperatures up to $2500^{\circ} \mathrm{C}$. In the case of the Macael marble (M), the linear elastic behaviour is also clear generally speaking, although a slight influence of temperature can be observed on the brittleness of the rock 
at 250 으. Finally, the Carrara marble (I) shows the highest ductility in relative terms. Even the curves at room temperature are not completely linear (especially close to the peaks), but it can be still assumed that it behaves as a quasi-brittle rock.

Floresta sandstone (F) Moleano limestone (C) Macael marble (M)

Carrara marble (I)
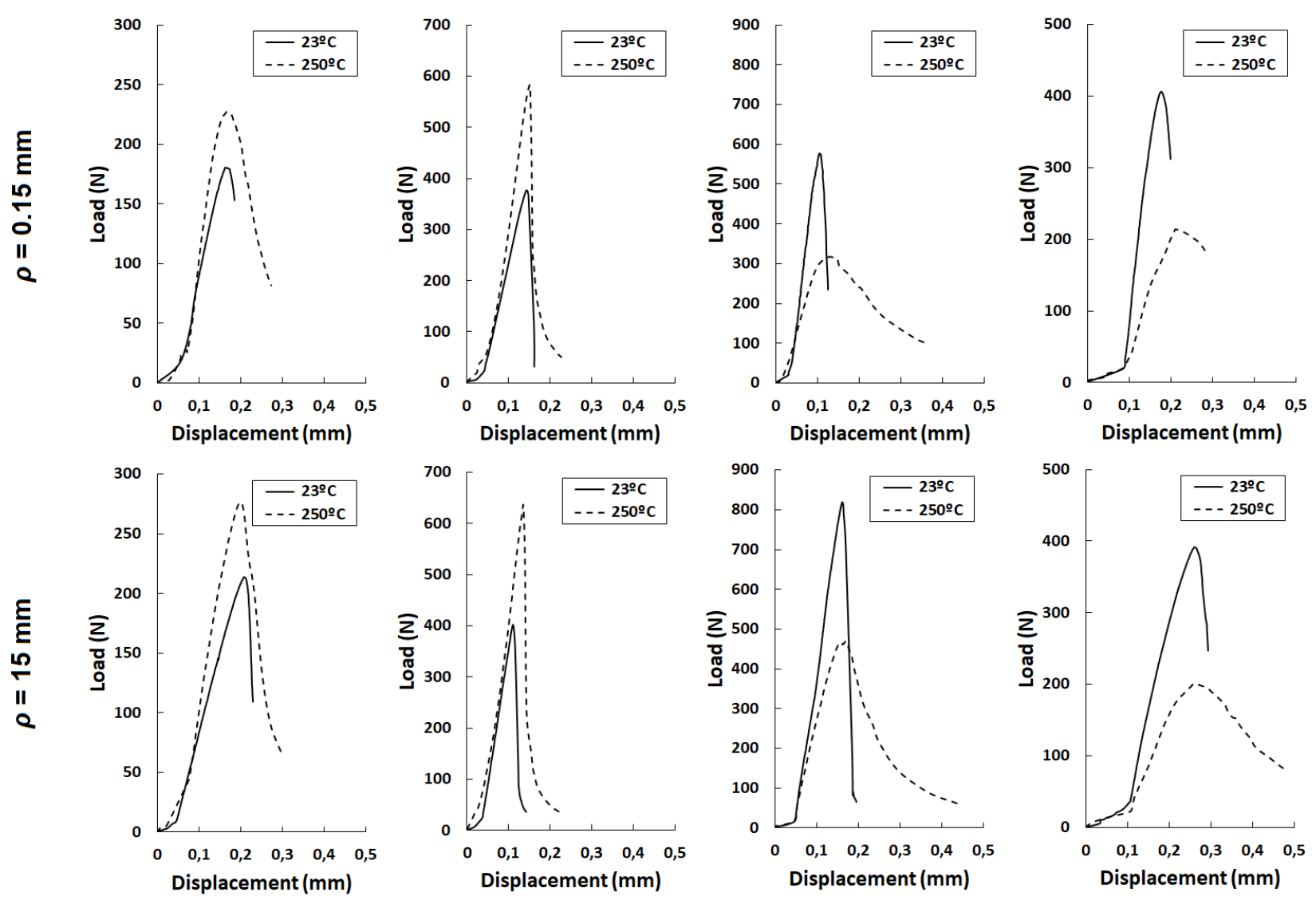

Fig. 4.- Load-displacement curves of the four-point bending tests at different temperatures.

Finally, Figure 5 shows some fracture surfaces of each of the analysed rocks at $250^{\circ} \mathrm{C}$, for the particular case of $\rho=15 \mathrm{~mm}$. As expected, no ductility is observed at macro-scale from the visual inspection.

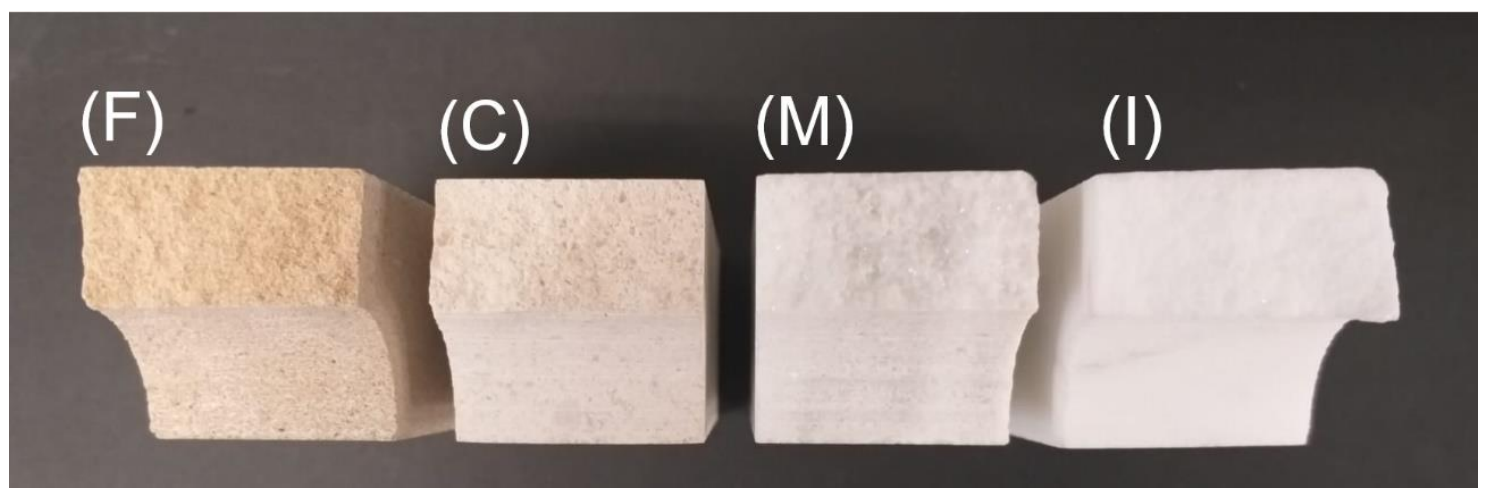

Fig. 5.- Fracture surface of the analysed rock specimens $(\rho=15 \mathrm{~mm})$ at $250^{\circ} \mathrm{C}$. 


\subsection{INFLUENCE OF TEMPERATURE ON THE TENSILE STRENGTH}

The influence of temperature on the tensile strength of rocks is irretrievably linked to their microstructure. The differential thermal expansion of adjacent mineral particles subjected to changes in temperature, and the presence of pores or cavities allowing that expansion define the thermal behaviour of rocks. Thus, as a consequence of the existing heterogeneity in rock composition, different responses can be distinguished among the wide casuistic of the considered rocks. Table 2 gathers the results of the Brazilian tests performed at different temperatures, including the mean values of the tensile strength of the selected rocks and their standard deviations. Likewise, Fig. 6 shows the variation with temperature of the tensile strength $\left(\sigma_{u}\right)$ of these rocks. The dots correspond to the individual tests and the solid lines represent the mean value.

Table 2.- Mean value and standard deviation of the tensile strength ( $\mathrm{MPa})$ of rocks at different temperatures. F: Floresta sandstone; C: Moleano limestone; M: Macael marble; I: Carrara marble.

(F)

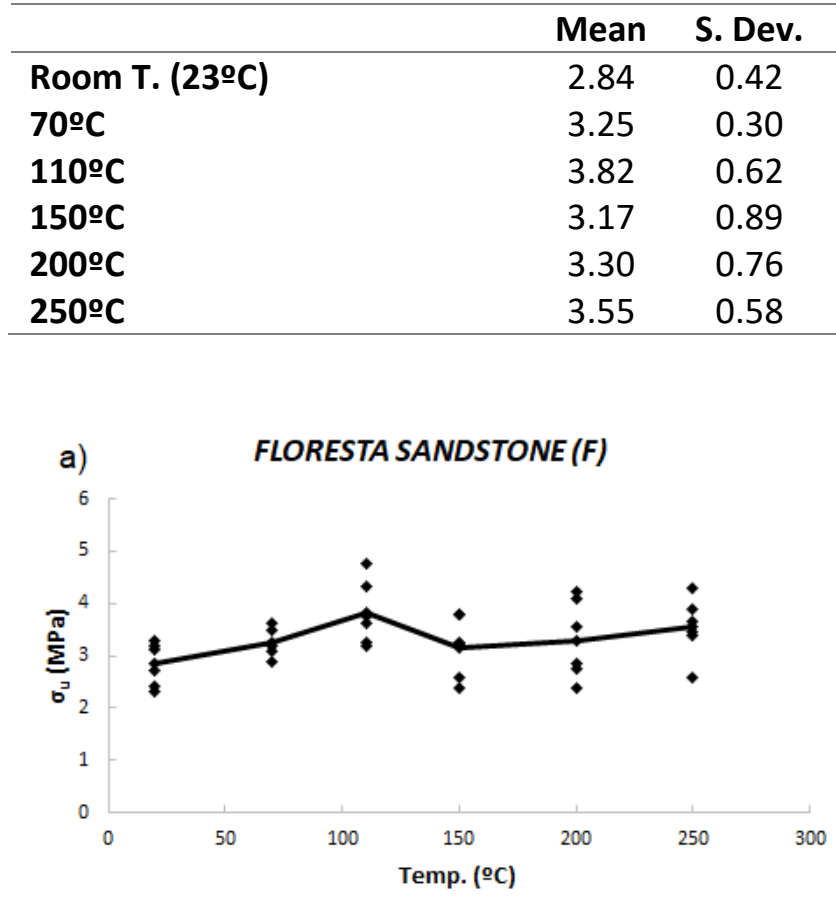

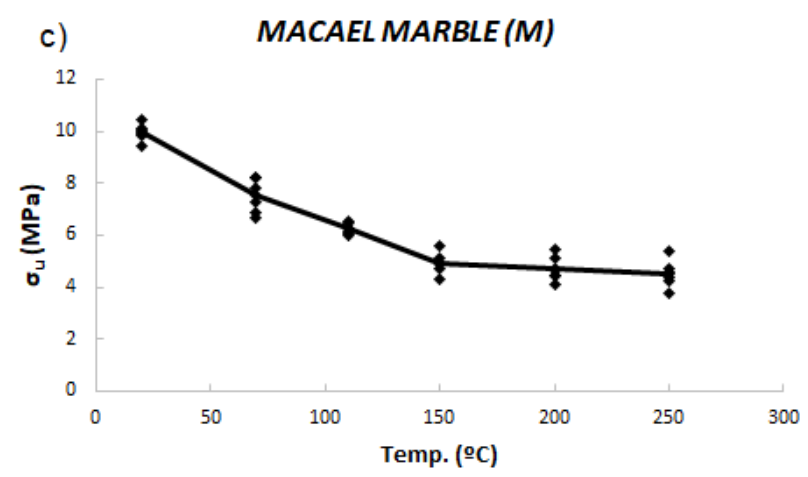

(C)

(1)

S. Dev.

$\begin{array}{cccccc}\text { Mean } & \text { S. Dev. } & \text { Mean } & \text { S. Dev. } & \text { Mean } & \text { S. Dev. } \\ 6.86 & 1.08 & 9.97 & 0.33 & 9.16 & 0.71 \\ 8.18 & 0.53 & 7.52 & 0.67 & 7.26 & 0.61 \\ 9.02 & 1.49 & 6.25 & 0.22 & 5.90 & 0.58 \\ 9.62 & 0.87 & 4.92 & 0.41 & 5.67 & 0.77 \\ 8.96 & 0.68 & 4.70 & 0.51 & 4.08 & 0.39 \\ 8.88 & 0.50 & 4.50 & 0.55 & 5.00 & 0.60\end{array}$

Fig. 6.- Variation of the tensile strength of the analysed rocks with temperature. 
Two clear trends can be observed in the obtained results. On the one hand, both the Floresta sandstone (F) and the Moleano limestone (C) undergo an increment of the tensile strength up to a certain temperature, after which this parameter slightly decreases (Figs. 6a and b). As displayed in Table 1, these two rocks reveal $16.3 \%$ and $6.4 \%$ of porosity, respectively. The initial increment of the tensile strength may be caused by the closure of these pores and micro-features as a consequence of the expansion of the mineral particles exposed to a thermal increment. ${ }^{39}$ By contrast, once a certain critical temperature is reached, the persistence of the thermal expansion between adjacent particles generates microcracks that explain the subsequent slight reduction of the tensile strength. ${ }^{40}$ Another possible reason explaining this behaviour is the effect of humidity within these two porous rocks, because there seems to be a change in the curves close to $110^{\circ} \mathrm{C}$ (Figs. $6 \mathrm{a}$ and b). Some authors ${ }^{42,51-52}$ have worked on the effect of water on the strength of rocks. According to Zuo et al., ${ }^{42}$ when temperature ranges from room to $200^{\circ} \mathrm{C}$, the effect of the pore pressure changes with temperature is not negligible. By contrast, humidity has no influence on the marbles (Figs. 6c and d) due to its null porosity and nearly null water absorption (Table 1).

Analysing Figs. $6 \mathrm{c}$ and d, both the Macael marble (M) and the Carrara marble (I), those with nearly null porosity, present from the beginning a clear reduction in the tensile strength as temperature gets higher. This strength reduction is assumed to be caused by the development of microcracks induced by differential thermal expansion of mineral particles with no internal space for growth. ${ }^{41}$

\subsection{INFLUENCE OF TEMPERATURE ON THE FRACTURE TOUGHNESS}

The variation of the fracture toughness with temperature also presents different behaviours depending on the microstructure of the analysed rock. Table 3 gathers the results of the four-point bending tests at different temperatures, considering only those corresponding to the smallest notch radii $(\rho=0.15 \mathrm{~mm})$ that have been assumed to behave as sharp cracks. Both the mean values of the fracture toughness and their standard deviations are indicated, once again according to the obtained experimental results.

Table 3.- Mean value and standard deviation of the fracture toughness (MPa. $\left.\mathrm{m}^{1 / 2}\right)$ of rocks at different temperatures. F: Floresta sandstone; C: Moleano limestone; M: Macael marble; I: Carrara Marble.

\begin{tabular}{lccccccccc}
\hline & \multicolumn{2}{c}{ (F) } & \multicolumn{2}{c}{ (C) } & \multicolumn{2}{c}{ (M) } & \multicolumn{2}{c}{ (I) } \\
\hline & Mean & S. Dev. & Mean & S. Dev. & Mean & S. Dev. & Mean & S. Dev. \\
\hline Room T. (23C) & 0.37 & 0.06 & 0.73 & 0.11 & 1.14 & 0.13 & 0.74 & 0.13 \\
$\mathbf{7 0}$-C & 0.43 & 0.07 & 0.96 & 0.06 & 1.16 & 0.24 & 0.75 & 0.14 \\
$\mathbf{1 5 0}$ C & 0.46 & 0.08 & 0.95 & 0.11 & 0.57 & 0.07 & 0.62 & 0.08 \\
$\mathbf{2 5 0}$-C & 0.45 & 0.08 & 1.07 & 0.17 & 0.72 & 0.12 & 0.50 & 0.17 \\
\hline
\end{tabular}

The fracture toughness of these rocks expresses their resistance to unstable crack propagation, or in other words, the fracture energy consumption rate required to generate new surfaces. The required fracture 
energy is reduced in the presence of thermally induced micro-cracks or can be increased with the closure of pores or cracks as a consequence of changes in temperature. Besides, the performed tests correspond to Mode I (opening case) loading conditions, in which the rocks are more sensitive to the presence of these microcracks. With all this, Fig. 7 displays the variation of the fracture toughness of the four selected rocks with temperature.
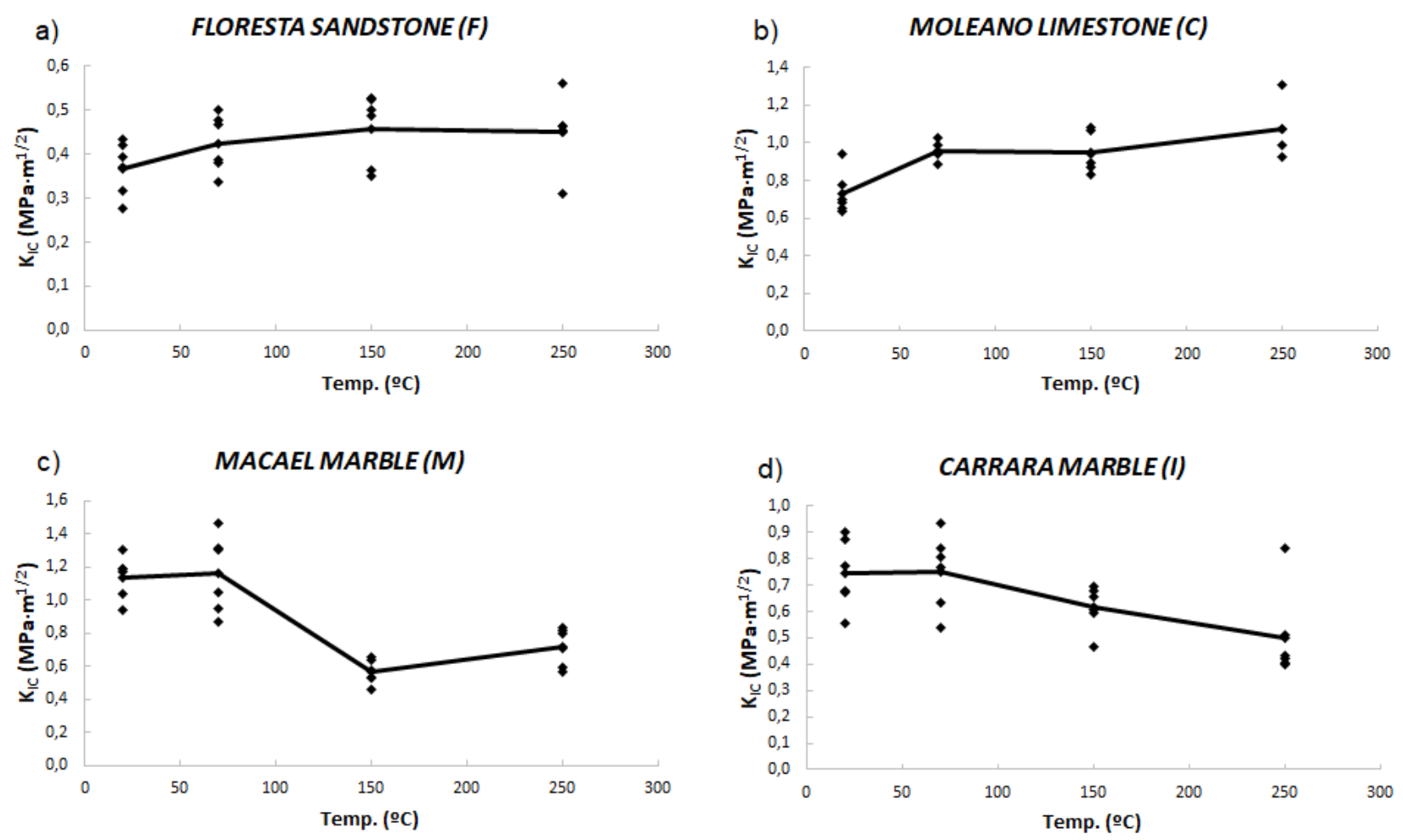

Fig. 7.- Variation of the fracture toughness of the analysed rocks with temperature.

The higher variability of the individual results shown in Fig. 7 in comparison to Fig. 6 could be caused by the precision of the diamond wire during the cutting process of the notch, which has led to slight differences in the notch lengths. Both the Floresta sandstone (F) and the Moleano limestone (C), those rocks with a certain porosity and water absorption capacity (Table 1), show a slight increment of the fracture toughness values with temperature (Figs. $7 \mathrm{a}$ and $\mathrm{b}$ ). This rise is likely to be caused again by the closure of the inner pores, which makes the propagation of the cracks more difficult and, therefore, higher fracture energy is required to generate new cracking surfaces. However, the increment of the fracture toughness is limited by a critical temperature. From a certain temperature onwards thermally induced microcracks arise, contributing to crack propagation and consequently reducing the fracture toughness. ${ }^{41}$ The effect of humidity could also have an important influence on their behaviour. ${ }^{42}$ By contrast, both marbles show an almost constant value of the fracture toughness up to approximately $70^{\circ} \mathrm{C}$ (Figs. $7 \mathrm{c}$ and d), after which it decreases. These marbles have no porosity, so the initial pore closure appreciated in the sandstone and the limestone is not shown here. 
Aliha and Ayatollahi ${ }^{53-54}$ collected some experimental results for the mode I fracture toughness $\left(K_{I C}\right)$ of several rocks at room temperature, obtained from semi-circular bend (SCB) and Brazilian disc (BD) specimens. They showed, for example, the results of a sandstone with $K_{I C}=0.47 \mathrm{MPa} \cdot \mathrm{m}^{1 / 2}$, two different limestones with $K_{I C}=0.42 \mathrm{MPa} \cdot \mathrm{m}^{1 / 2}$ and $0.24 \mathrm{MPa} \cdot \mathrm{m}^{1 / 2}$ and three marbles with $K_{I C}$ varying from $0.933-$ $1.06 \mathrm{MPa} \cdot \mathrm{m}^{1 / 2}$, one of them being an Italian light marble $\left(K_{I C}=0.933 \mathrm{MPa} \cdot \mathrm{m}^{1 / 2}\right)$ similar to the studied Carrara marble (I) with $K_{I C}=0.74 \mathrm{MPa} \cdot \mathrm{m}^{1 / 2}$ at room temperature. The effect of temperature on the rock fracture toughness have been studied by different researchers, reporting similar trends at the analysed range of temperatures. ${ }^{35-37,40-42}$ For example, Zuo et al. ${ }^{42}$ performed several three-point bending tests of siltstone prismatic samples at different temperatures and observed that the fracture toughness varied from approximately $0.98 \mathrm{MPa} \cdot \mathrm{m}^{1 / 2}$ at $25{ }^{\circ} \mathrm{C}$ to $0.86 \mathrm{MPa} \cdot \mathrm{m}^{1 / 2}$ at $300 \circ \mathrm{C}$. Similarly, Feng et al. ${ }^{36}$ reported the case of a sandstone in which the fracture toughness increased from approximately $0.99 \mathrm{MPa} \cdot \mathrm{m}^{1 / 2}$ to $1.10 \mathrm{MPa} \cdot \mathrm{m}^{1 / 2}$ from $20 \circ \mathrm{C}$ to $100 \circ \mathrm{C}$ and then showed a decrease to $0.87 \mathrm{MPa} \cdot \mathrm{m}^{1 / 2}$ at $400 \circ \mathrm{C}$. In this case $\mathrm{SCB}$ specimens were used. So, in general terms, the obtained values of the fracture toughness and their variation with temperature (Table 3) fall within the same range as that observed in the literature for other rocks.

\subsection{THERMAL EXPANSION}

In order to determine the extent and the degree of influence of the pore closure with temperature over the analysed critical parameters so far, the dilatation of $180 \times 30 \times 30 \mathrm{~mm}$ size rock specimens (without notches) has also been studied by means of a digital comparator with an accuracy of a hundredth of a millimetre. Fig. 8 represents the observed external longitudinal dilatation curves for 3-4 rock samples (S.1S.4) from room temperature up to $250^{\circ} \mathrm{C}$. Two main mechanisms can be distinguished in the graphs. Firstly, in those rocks with significant porosity and internal space for the expansion of the particles, the curves show an initial expansion during the first $25^{\circ} \mathrm{C}$ of temperature increment, followed by a quasi-horizontal slope in which there is almost no external expansion with the rise of temperature (Figs. 8a and b). This behaviour is maintained up to around $90^{\circ} \mathrm{C}$ for the Floresta sandstone $(\mathrm{F})$ and $110^{\circ} \mathrm{C}$ for the Moleano limestone (C), and could correspond to the inner expansion, where the existing pores, cavities or micro-cracks get closed. Once a critical temperature is reached, the main mechanism changes and the slope of the curves becomes steeper. This second mechanism seems to be dominated by the external expansion of the rocks and the influence of the pore closure becomes negligible. In the case of the marbles (Figs. $8 \mathrm{c}$ and d), the first defined mechanism is not clearly visible and a significant external growth is observed from the beginning. In the particular case of the Macael marble (M), a higher variability is shown between the four measured specimens (Fig. 8c) and some changes in the curvatures are observed comparing to the Carrara marble (I) in Fig. $8 \mathrm{~d}$. However, the trend seems to be the same in all of them and the governing mechanism corresponds 
to the external expansion in both marbles. Finally, it can also be concluded that the thermal dilatation coefficient in the marbles is much higher than in the sandstone and the limestone, which could facilitate the appearance of microcracks.
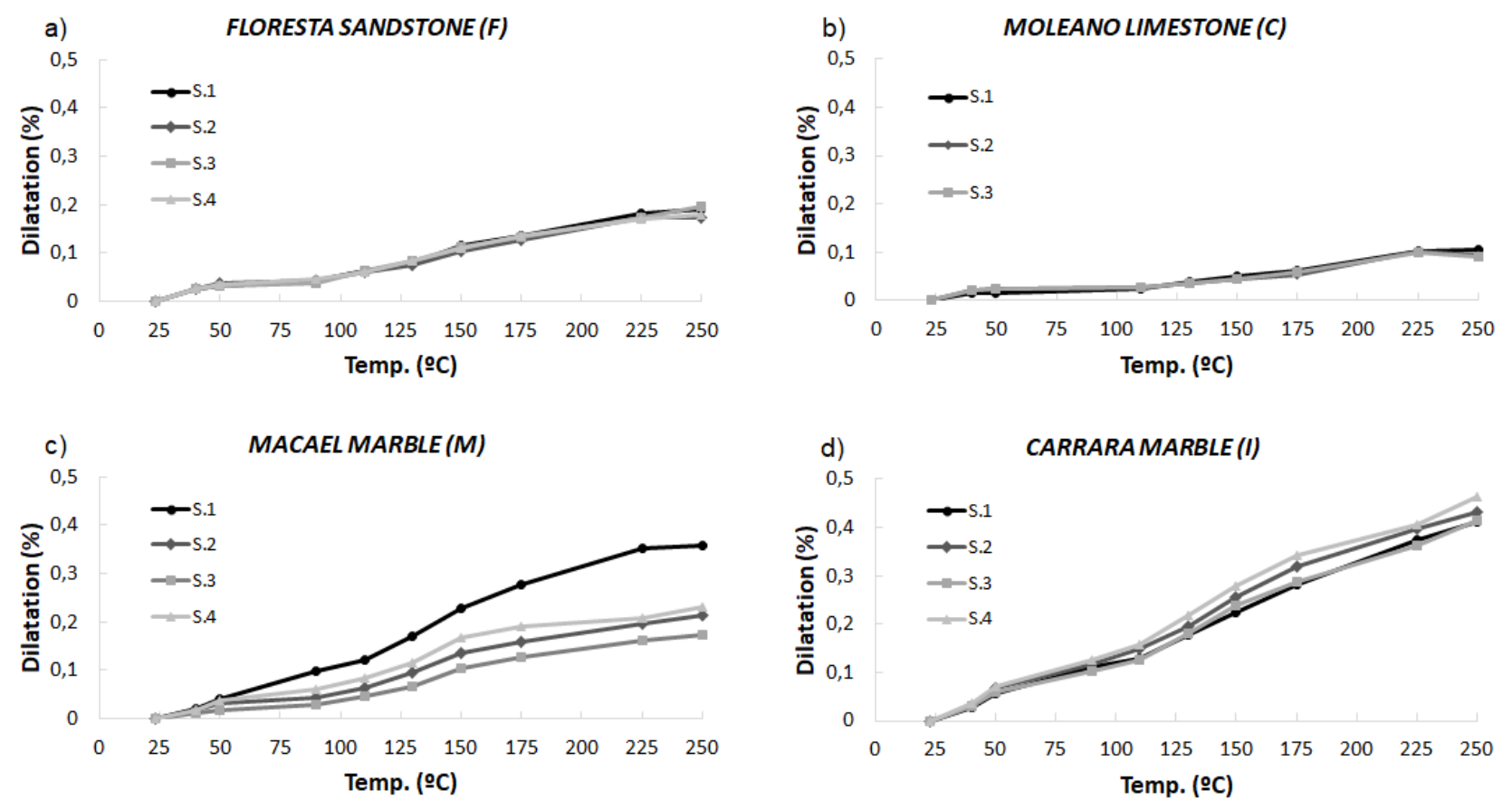

Fig. 8.- Dilatation curves of the analysed rocks with temperature.

\subsection{INFLUENCE OF TEMPERATURE ON THE NOTCH EFFECT AND THE CRITICAL DISTANCE}

Based on the obtained parameters $\left(\sigma_{u}\right.$ and $\left.K_{I C}\right)$ and their variation with temperature, the critical distance $(L)$ can be calculated using Eq. (1). Table 4 collects the different results for each of the analysed rocks and temperatures, indicating both the mean values and the corresponding standard deviation calculated from all the possible combinations of $\sigma_{u}$ and $K_{I C}$.

Table 4.- Mean value and standard deviation of the calculated critical distance ( $\mathrm{mm}$ ) according to Eq. (1). F: Floresta sandstone; C: Moleano limestone; M: Macael marble; I: Carrara Marble.

\begin{tabular}{lcccccccc}
\hline & \multicolumn{2}{c}{ (F) } & \multicolumn{2}{c}{ (C) } & \multicolumn{2}{c}{ (M) } & \multicolumn{2}{c}{ (I) } \\
\hline & Mean & S. Dev. & Mean & S. Dev. & Mean & S. Dev. & Mean & S. Dev. \\
\hline Room T. (23C) & 5.82 & 2.42 & 4.02 & 2.10 & 4.20 & 0.90 & 2.19 & 0.79 \\
70C & 5.66 & 1.84 & 4.43 & 0.76 & 8.00 & 3.26 & 3.59 & 1.33 \\
150C & 7.52 & 3.72 & 3.19 & 0.83 & 4.33 & 1.23 & 3.99 & 1.36 \\
250C & 5.73 & 2.81 & 4.77 & 1.46 & 8.62 & 3.16 & 3.65 & 2.83 \\
\hline
\end{tabular}

Analysing the mean values of the critical distance shown in Table 4 for the different rocks, the values of $L$ vary with temperature from 5.66 to $7.52 \mathrm{~mm}$ in the case of the Floresta sandstone (F), from 3.19 to 4.77 $\mathrm{mm}$ in the Moleano limestone (C), from 4.20 to $8.62 \mathrm{~mm}$ in the Macael marble (M) and from 2.19 to 3.99 
$\mathrm{mm}$ in the Carrara marble (I). Aliha and Ayatollahi ${ }^{53-54}$ gathered some data on the FPZ for a variety of similar rocks. They reported the cases of three different marbles with $L$ values varying from 1.20 to $6.40 \mathrm{~mm}$, two types of limestones with $L=4.60-10.40 \mathrm{~mm}$ and a sandstone with $L=2.90 \mathrm{~mm}$, among others. The order of magnitudes are reasonably in the same range in all the cases and the differences are caused by the different petrographic properties.

Likewise, Fig. 9 displays the variation of the critical distance $(L)$ with temperature for each rock. In this case, the figure is composed of box-and-whisker plots representing, from top to bottom, the maximum value, the third quartile, the median, the first quartile and the minimum value of the obtained results for $L$. These statistical values are derived, as in the case of the values in Table 4, from the calculation of $L$ (Eq. 1) with all the possible combinations of the individual test results of $K_{I C}$ and $\sigma_{u}$. There are no clear tendencies of the variation of $L$ with temperature according to the plots in Fig. 9.
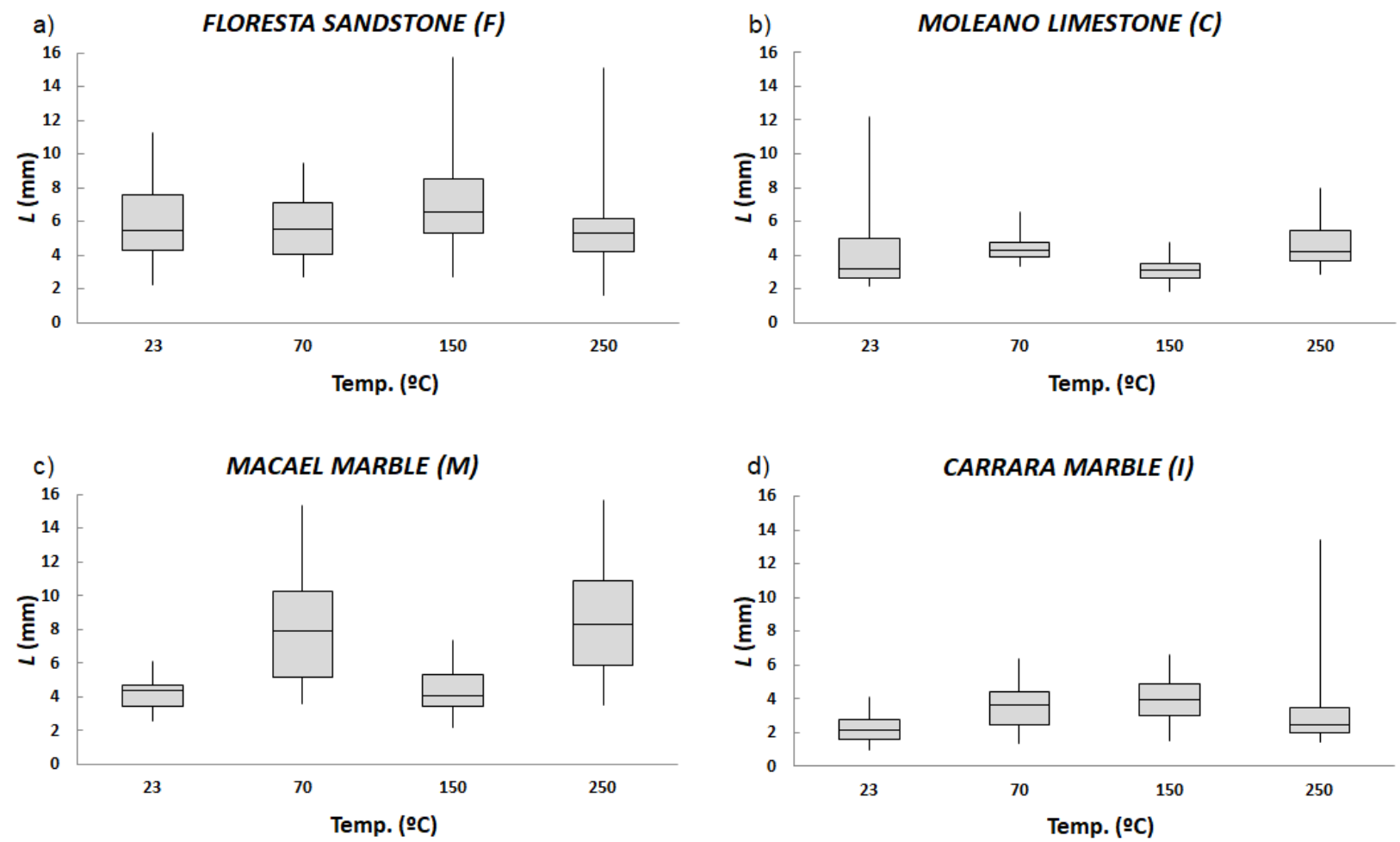

Fig. 9.- Variation of the critical distance $(L)$ with temperature for each rock.

On the other hand, dealing with the notch effect analysis, Fig. 10 depicts the experimental results of all the performed four-point bending tests. The graphs included within this figure represent the apparent fracture toughness $\left(K_{I N}\right)$ against the square root (just for graphic representation reasons) of the notch radii for each material and temperature. The dots correspond to the experimental results of every individual test according to Eq. (9), in which the apparent fracture toughness $\left(K_{I N}\right)$ is considered instead of the real fracture toughness $\left(K_{I C}\right)$. The dashed lines represent the calculated curves according to the Line Method of the TCD 
(Eq. (8)), using the mean values of the fracture toughness and the critical distance gathered in Tables 3 and 4, respectively. By contrast, the solid lines correspond to the best-fit curves according once again to the Eq. (8) of the LM, in which the value of the fracture toughness has been fixed leaving the critical distance $L$ as the only free variable.
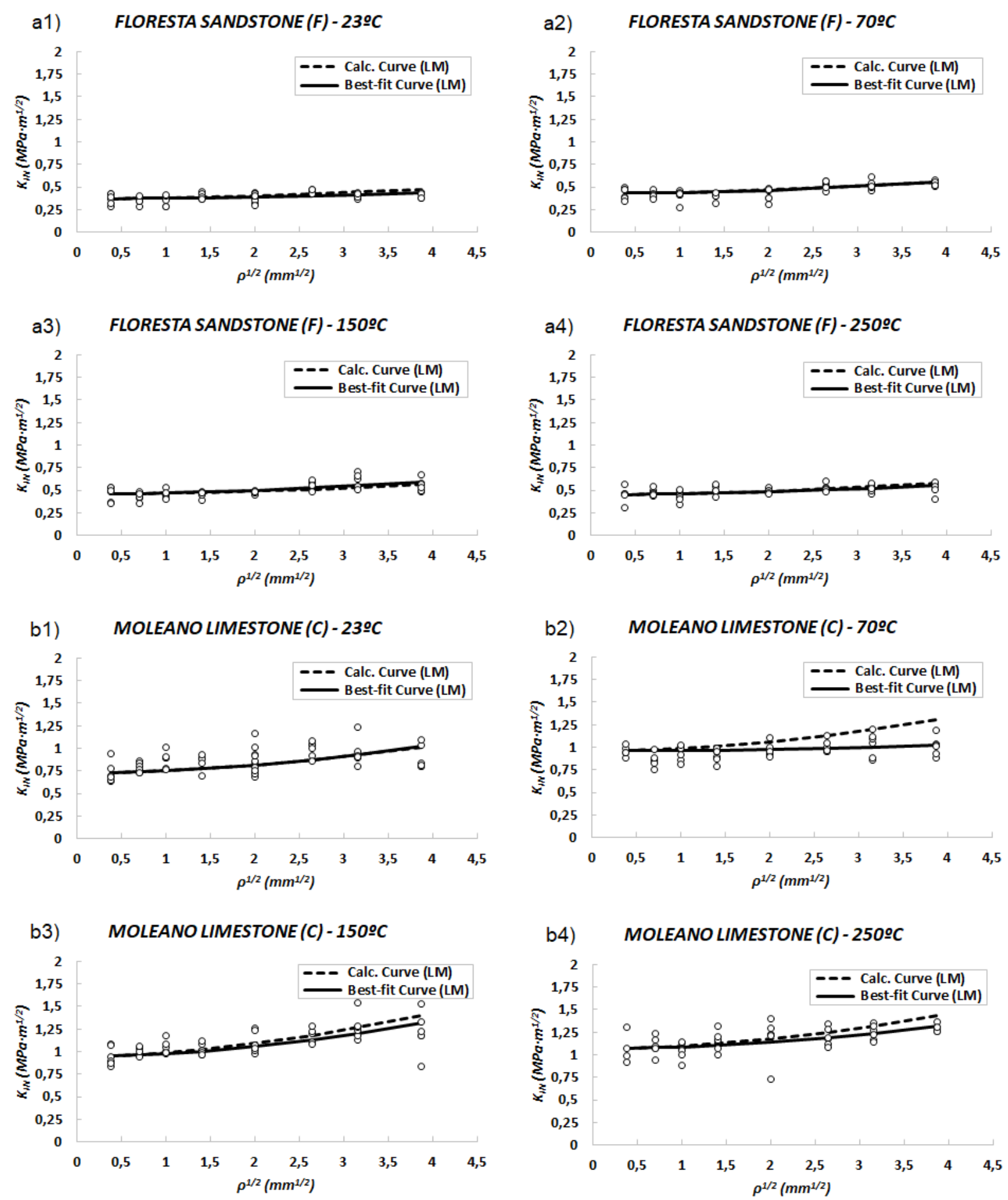

Fig. 10.- Test results of the apparent fracture toughness $\left(K_{I N}\right)$ and comparison with the $L M$ of the TCD for each material and temperature. 

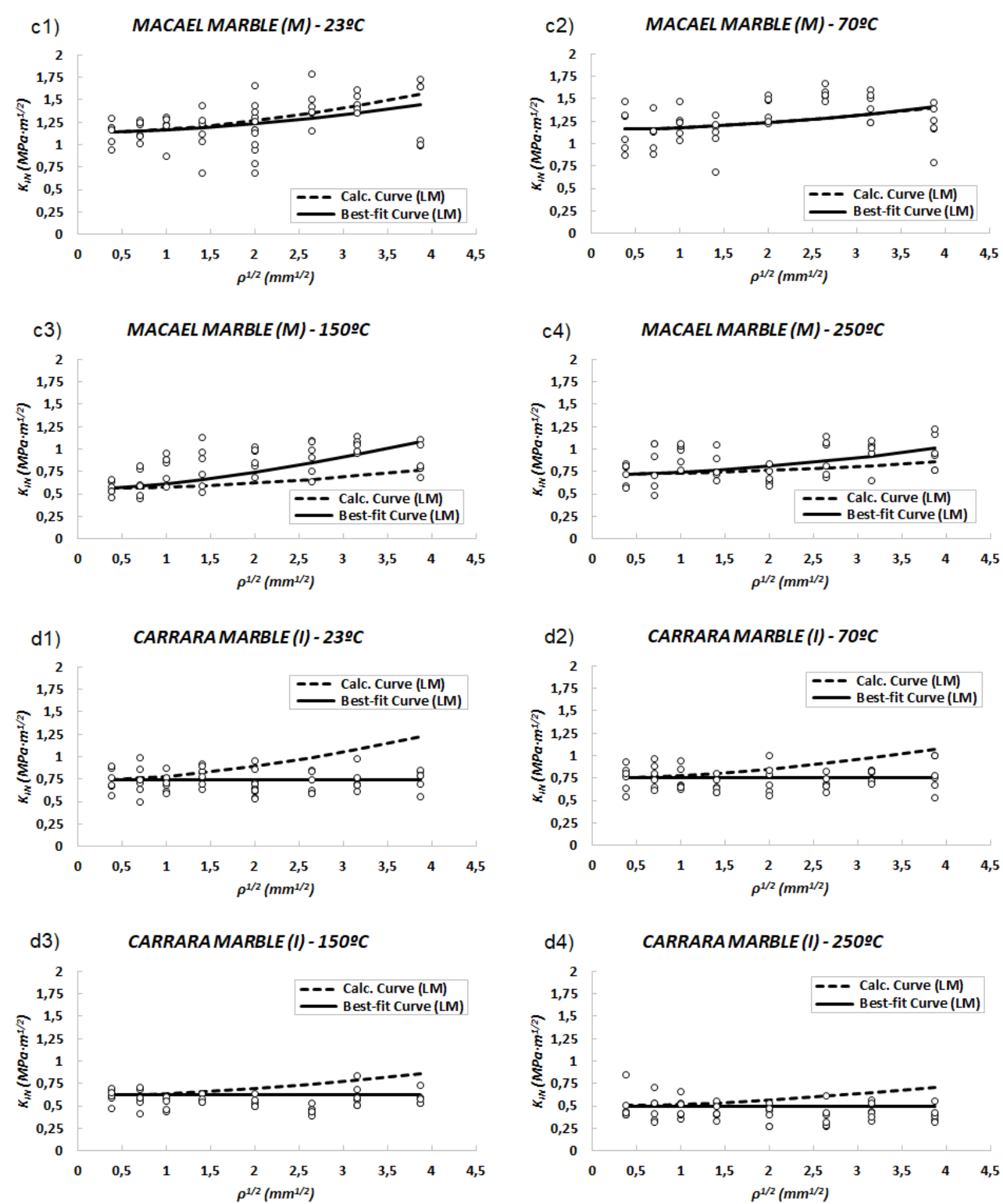

Fig. 10.- (Continued).

The notch effect may be appreciated in the results shown in Fig. 10, since the fracture toughness varies with the considered notch radius except for the Carrara marble (I). According to $\operatorname{Taylor}^{23}$, when the notch radius is smaller than the critical distance $(\rho<L)$ of a certain material, the notch will behave as a crack of the same length $\left(K_{I N}=K_{I C}\right)$. This means that the notch effect can be neglected and that ordinary fracture 
mechanics can be used to analyse notches with a radius smaller than a few millimetres in the case of rocks. In general, a reasonable agreement between TCD predictions and laboratory results is obtained in most of the cases except in the Carrara Marble (I). This rock does not show a clear trend and the notch effect is not appreciated (Fig. 10d) as expected from a previous work of the authors. ${ }^{12}$ Larger radii should be tested to try to identify the notch effect. In addition, some scatter was noticed on the experimental results depending on the block used to extract the different specimens, which introduces an important source of variability into the results.

For the sake of clarity, the results corresponding to the Point Method (Eq. (7)) of the TCD are not included in Fig. 10 and have only been summarised in Table 5. This table collects the values of the critical distances obtained from the best-fit curves for both the Point Method (PM) and the Line Method (LM), keeping the fracture toughness fixed (Table 3). It can be easily concluded from Fig. 10 that for the largest notch radii, the adjustment between the calculated curves (dashed lines) and the best-fit curves (solid lines) becomes less accurate (e.g. Figs. 10a1, 10b2). Several reasons can explain this generality: First, the value of $K_{I C}$ is fixed for the best-fit curves and, therefore, both the dashed and solid lines start at the same point and the differences are more significant for the largest radii. However, it has been checked that leaving $K_{I C}$ as a free variable for the best-fit curves provides similar results in most of the cases. In the case of Fig. 10b2, for example, the best-fit curve (solid line) would start with a lower apparent fracture toughness $\left(K_{I N}\right)$ for $\rho=$ $0.15 \mathrm{~mm}$ if $K_{I C}$ was free. Consequently, the obtained best-fit value of $L$ according to the $\mathrm{LM}$ is so high for the Moleano limestone (C) at $70 \circ \mathrm{C}$ (Table 5). Secondly, both Eq. (7) and Eq. (8) are based on the stress distribution of Creager and Paris, ${ }^{1}$ which is theoretically only valid for long and narrow notches. The apparent fracture toughness $\left(K_{I N}\right)$ values for the largest notch radii tend to reduce due to Creager and Paris, ${ }^{1}$ and therefore, the best-fit curves also decrease. Nevertheless, despite this restriction, reasonable results are obtained beyond this limitation in many of the cases (e.g. Figs. 10a2, 10b1, 10c2). This inaccuracy explains the differences between the calculated (Table 4) and the best-fit values of the critical distance provided in Table 5. However, the consequences of these variations are rather limited from the point of view of the apparent fracture toughness predications obtained through Eqs. (7) and (8), given that in such expressions the critical distance is squared, and moderate variations of this parameter cause small variations in the resulting predictions.

All the results in Table 5 are consistent with those indicated in Fig. 9 and do not show any tendency with temperature either. The values of $L$ corresponding to the LM and the Carrara marble (I) are out of order due to the almost null slope of the best-fit curves (Figs. 10d) that leads to extremely high values of the critical distance. For this reason, these values have not been included in the table. 
Table 5.- Summary of the best-fit values of the critical distance $L(\mathrm{~mm})$ according to the PM and the LM of the TCD. F: Floresta sandstone; C: Moleano limestone; M: Macael marble; I: Carrara Marble.

\begin{tabular}{|c|c|c|c|c|}
\hline & (F) & (C) & (M) & (I) \\
\hline Room T. (23ㄷ) - Best fit of $L(\mathrm{PM})$ & 3.66 & 2.29 & 2.85 & 8.62 \\
\hline 70 ㄷ - Best fit of $L(\mathrm{PM})$ & 2.78 & 5.13 & 3.41 & 6.60 \\
\hline $150^{\circ} \mathrm{C}$ - Best fit of $L(\mathrm{PM})$ & 2.79 & 2.40 & 1.06 & 10.52 \\
\hline 250 ㄷ - Best fit of $L(\mathrm{PM})$ & 3.39 & 3.35 & 2.38 & 16.28 \\
\hline Room T. $\left(23^{\circ} \mathrm{C}\right)$ - Best fit of $L(\mathrm{LM})$ & 9.94 & 3.96 & 6.02 & - \\
\hline $709 \mathrm{C}-$ Best fit of $L(\mathrm{LM})$ & 5.86 & 25.43 & 7.74 & - \\
\hline 150 -C - Best fit of $L(L M)$ & 5.63 & 4.12 & 1.37 & - \\
\hline 250 ㄷ - Best fit of $L(\mathrm{LM})$ & 7.45 & 7.43 & 3.91 & - \\
\hline
\end{tabular}

Finally, Fig. 11 summarises the best-fit curves from Fig. 10, representing, together for each rock, the results corresponding to the four considered temperatures. As expected from the analysis of the influence of temperature on the fracture toughness of the rocks (Fig. 10), in the case of the Moleano limestone (C) and the Floresta sandstone (F) the curves rise with temperature, while for the marbles the curves go down. However, the changes in the slopes of the curves are very limited, suggesting that temperature does not have a strong influence on the notch effect. In the particular case of the quasi horizontal curve corresponding to the Moleano limestone $(\mathrm{C})$ at $70^{\circ} \mathrm{C}$ (Fig. 11b), the curve would be approximately parallel to the rest if $K_{I C}$ was left as a free variable, which can indicate that the experimental tests may have not properly defined this particular parameter.
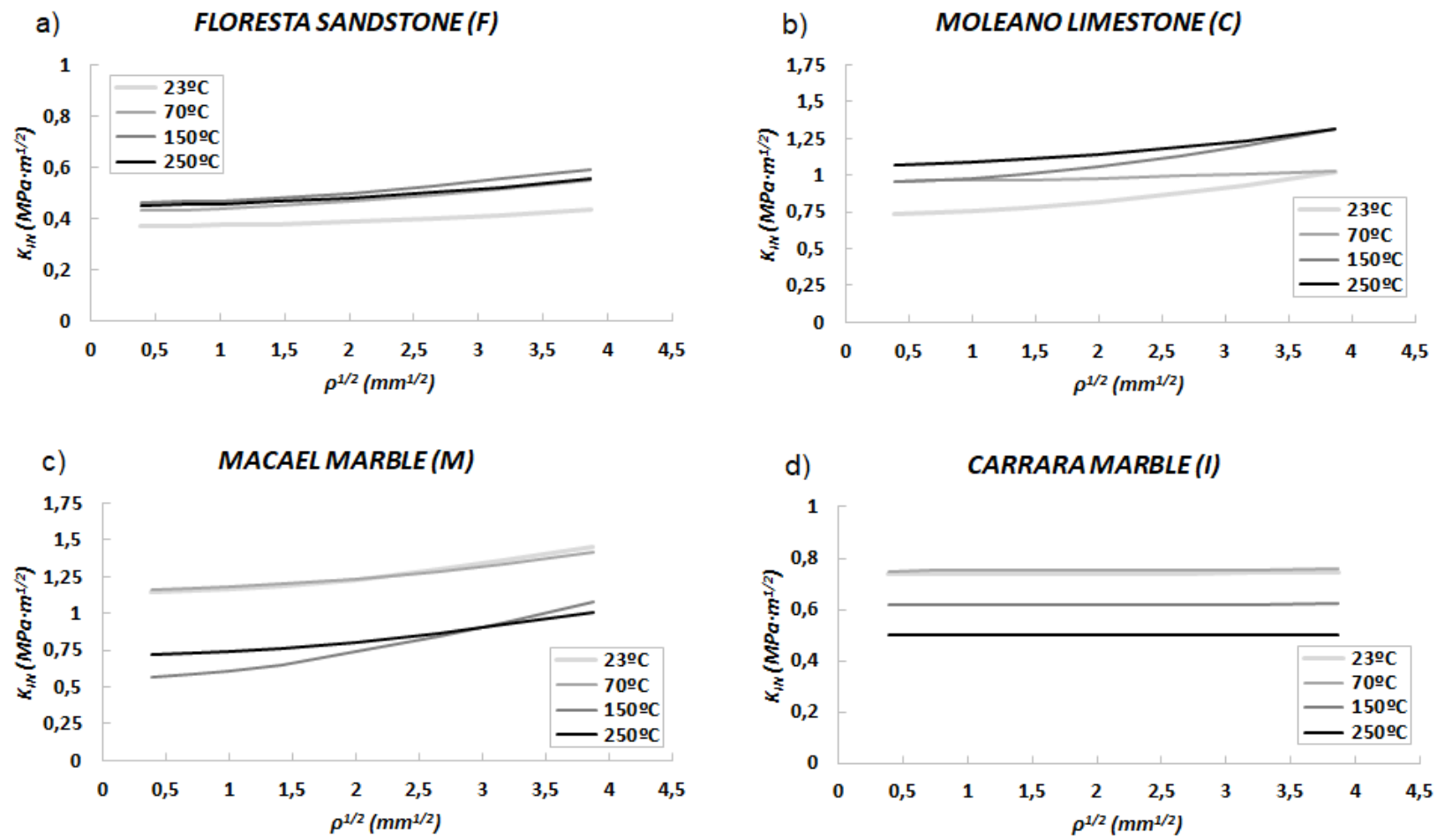

Fig. 11.- Summary of the best-fit apparent fracture toughness curves for each rock and temperature. 


\subsection{ROCK FRACTURE PREDICTION THROUGH THE THEORY OF THE CRITICAL DISTANCES}

Once $\sigma_{u}\left(=\sigma_{0}\right)$ and $K_{I C}$ are characterised (Tables 2 and 3), $L$ may be obtained (Eq. (1) and Table 4 ) and it is straightforward to perform a fracture prediction. To this end, Eq. (4) must be applied, with $K_{I}$ following Eq. (9) and $K_{I N}$ following Eq. (7) (PM) or Eq. (8) (LM). The values of $K_{I C}$ used in $K_{I N}$ predictions are those previously gathered in Table 3, obtained from the specimens with $\rho=0.15 \mathrm{~mm}$ (those that are assumed to behave as cracks). The resulting estimation of the predicted failure load $\left(F_{T C D}\right)$ is (when using the $L M$ ):

$F_{T C D}=\frac{b \cdot h^{1 / 2}}{Y} K_{I C} \sqrt{\frac{\rho}{4 L}+1}$

With all this, Fig. 12 displays the different rock fracture predictions for each rock and temperature using the LM. The plots represent the ratio between the predicted failure load $\left(F_{T C D}\right)$ and the experimental failure load $\left(F_{E X P .}\right)$ obtained from the four-point bending tests, against the notch radii $(\rho)$. The dots correspond once again to the individual test results, while the solid line indicates the average fracture prediction for each notch radii. The horizontal solid line $\left(F_{T C D} / F_{E X P .}=1\right)$ stands for the exact prediction. Thus, the values below this line are underestimating and the values above are overestimating the failure load. Moreover, it is a common practice in fracture mechanics to define a strip of $\pm 20 \%$ (horizontal dashed lines) as a boundary of good accuracy of fracture predictions. This envelope comprises the intrinsic uncertainties of the performed laboratory tests as well as the variability of the fracture results due to the heterogeneous nature of the rocks.
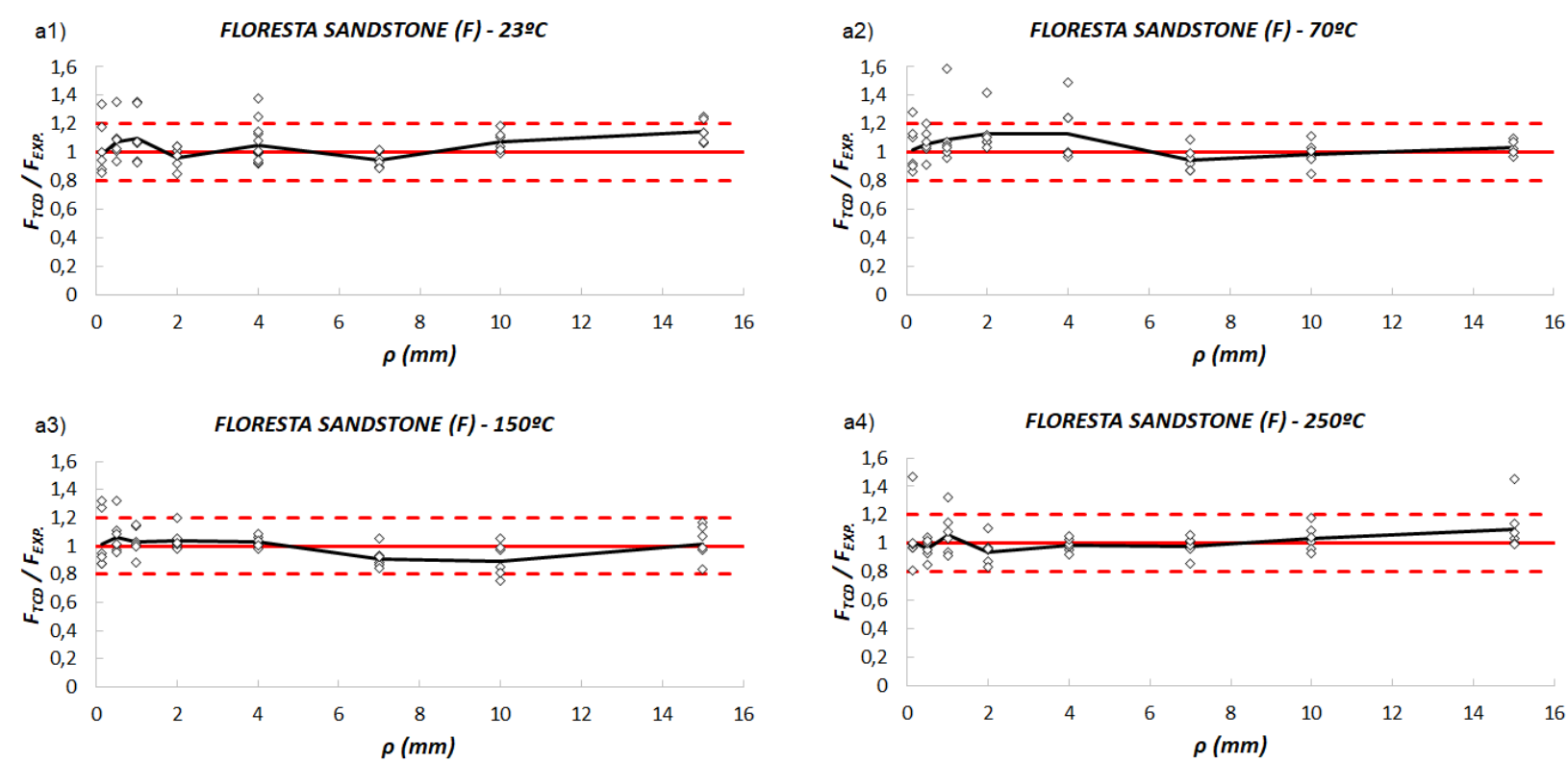

Fig. 12.- Rock fracture predictions according to the $L M$ of the TCD for each rock and temperature. 

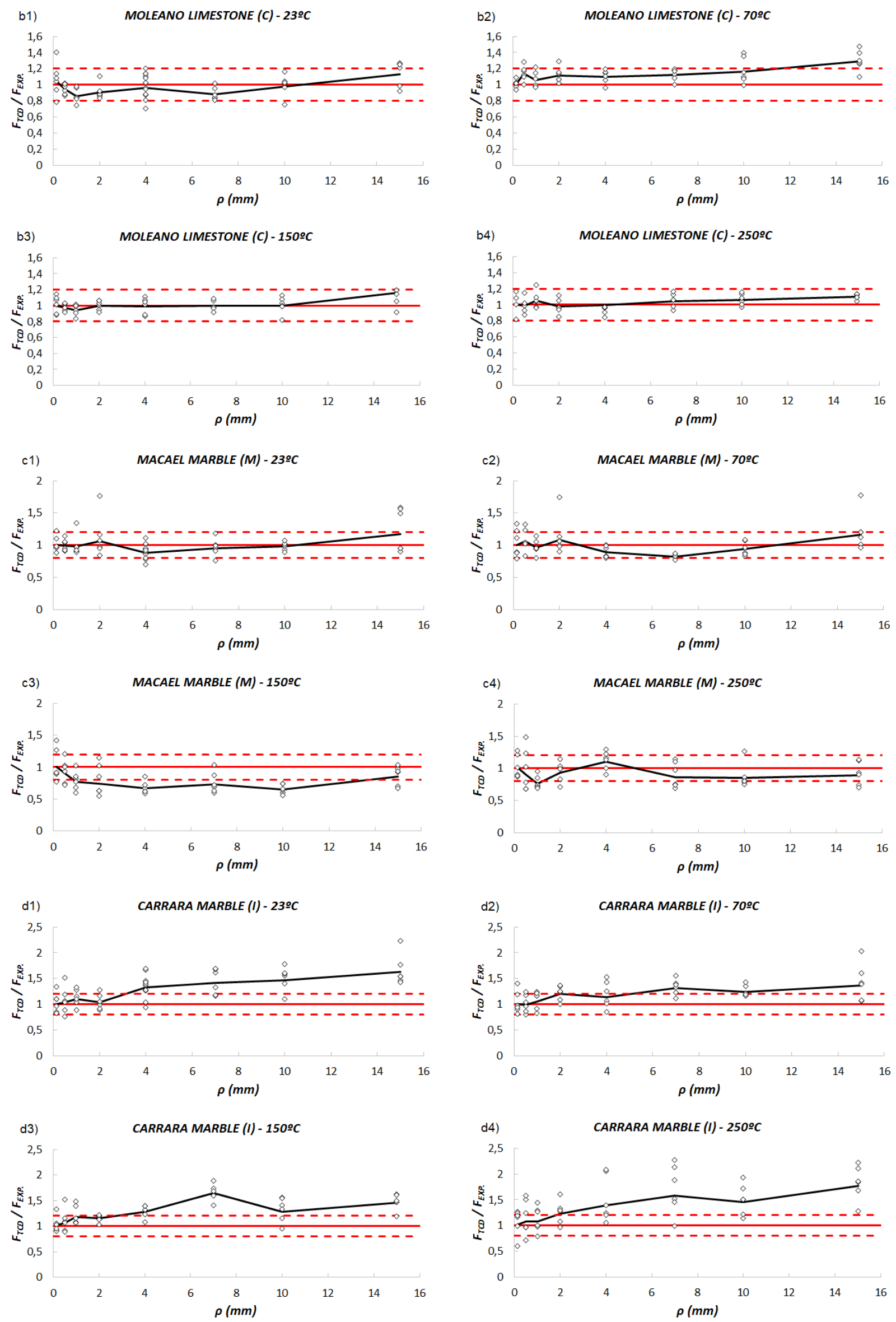

Fig. 12.- (Continued). 
Good predictions are generally obtained even for the largest notches beyond the application range of the Creager and Paris ${ }^{1}$ equation. Comparing Fig. 10 and Fig. 12, in those cases in which the calculated apparent fracture toughness curves are below the best-fit curves (e.g. Fig. 10c3), the fracture predictions tend to underestimate the failure loads (e.g. Fig. 12c3) and vice versa. As expected, the Carrara Marble (I) does not offer such good predictions (Fig. 11d) as the rest of the rocks, and further investigation is needed. These worse failure load predictions could be explained by the lower degree of linearity shown in the loaddisplacement curves in Fig. 4, which is not necessarily associated to the high temperatures, as similar results are also observed at room temperature. All the curves in Fig. 12 are obtained using the value of $L$ derived from the tensile strength (Eq. (1)), and therefore, the LEFM is being considered when using the TCD. Calibrating the critical distance would probably lead to more accurate predictions as the non-linearity would be absorbed.

Finally, Fig. 13 shows some of the representative fracture trajectories obtained from the tests for each rock and notch radius. The particular samples shown in Fig. 13 correspond to $150^{\circ} \mathrm{C}$ but no differences were observed in the trajectories with temperature. Generally speaking, the cracking process starts at the notch tip and propagates vertically as expected from pure bending moment. However, as the notch radius gets larger, the stress concentration at the notch tip gets smaller. Thus, other aspects as the presence of grain boundaries, the statistical distribution of the grains and pores or weaker zones close to the notch tip may have an influence on the starting point of the crack propagation in the case of the largest notches. This also causes a statistical variation of the failure load (Fig. 12).

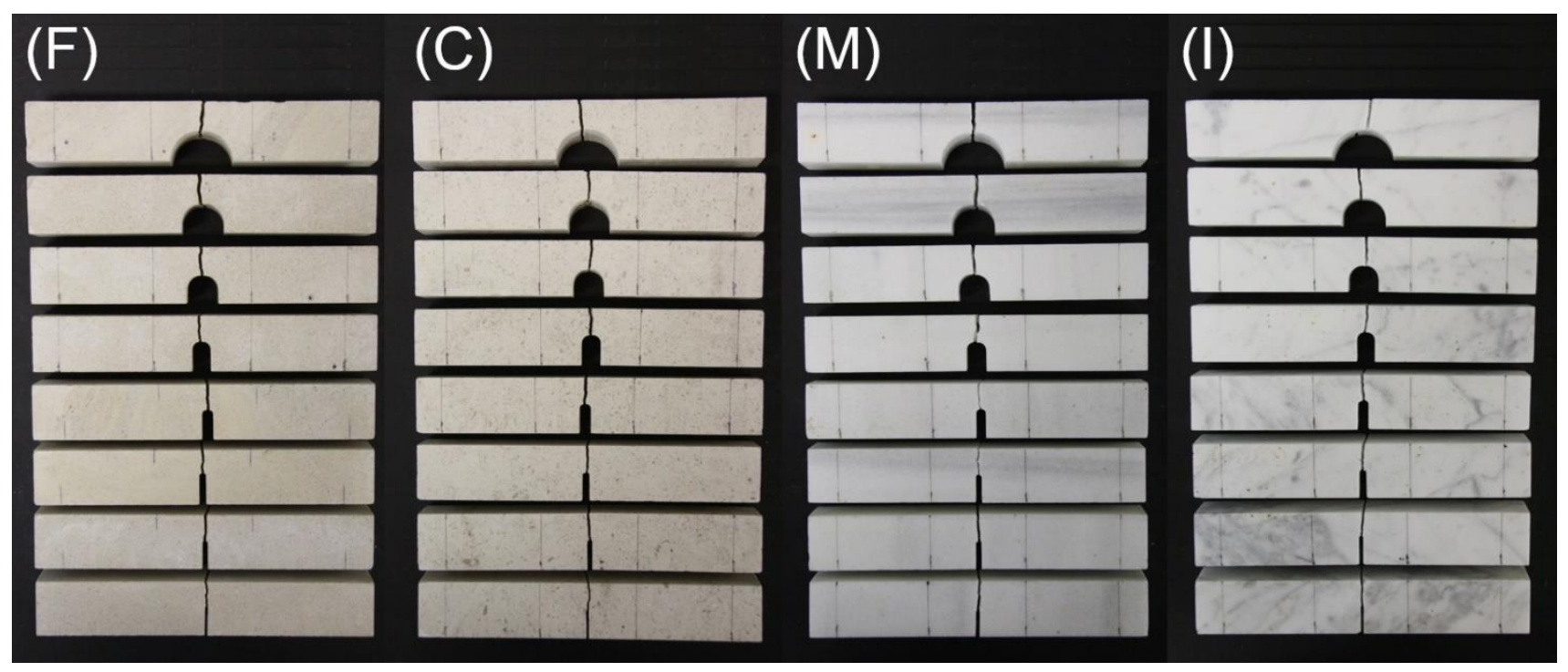

Fig. 13.- Representative fracture trajectories of the SENB samples with different notch radii. 


\section{CONCLUSIONS}

This paper studies the variation of the notch effect with temperature and presents the fracture analysis of four different types of rocks through the so called TCD. The research considers the temperature as a new variable and studies its influence on the key parameters governing the fracture behaviour of the rocks: the tensile strength $\left(\sigma_{u}\right)$, the fracture toughness $\left(K_{I C}\right)$ and the critical distance $(L)$. The results are based on an exhaustive and systematic experimental campaign, which offers a new valuable database on the fracture properties of 4 different rocks at different temperatures, as those common in geothermal applications.

Regarding the influence of temperature on the critical parameters studied, two main mechanisms are distinguished: the Floresta sandstone (F) and the Moleano limestone (C) develop an increment of the tensile strength $\left(\sigma_{u}\right)$ and the fracture toughness $\left(K_{I C}\right)$ up to a certain critical temperature. This increment is likely to be caused by the closure of the existing pores or microcracks during the initial heating stages. When the critical temperature is reached, the main mechanism changes and a slight decrease in the tensile strength and the fracture toughness is observed. This strength reduction is due to the appearance of new thermally induced microcracks as a consequence of a differential expansion between adjacent internal particles of the rocks. Another possible reason explaining the behaviour of the two analysed porous rocks is the effect of humidity, as the pore pressure variations might contribute to the changes in their behaviour. By contrast, in the case of the Macael marble (M) and the Carrara marble (I), those rocks with null porosity, only this second mechanism (i.e., the appearance of microcracks) is shown, since the decrease in the tensile strength and fracture toughness is appreciated practically from the onset of the thermal increment. The critical distance $(L)$ depends on the $K_{I C} / \sigma_{u}$ ratio, and although both $K_{I C}$ and $\sigma_{u}$ follow similar trends with temperature, $L$ does not show any clear tendency with temperatures.

The notch effect, which is related to the values of $L$, has proven to be evident and substantial in all of the rocks except in the Carrara marble (I). Broadly speaking, there does not seem to be any change in the notch effect of the rocks with temperature, as the tendencies of the apparent fracture toughness $\left(K_{I N}\right)$ curves remain approximately parallel and only the absolute values change according to the real fracture toughness $\left(K_{I C}\right)$ variations with temperature.

Finally, the TCD has proven to provide reasonable fracture load predictions (except for the Carrara marble (I)) within a strip of $\pm 20 \%$ with respect to the mean experimental failure loads. In this work, the stress distribution function defined by Creager and Paris ${ }^{1}$ was used to apply the TCD, and consequently, slightly poor predictions were obtained outside its applicability (e.g., $\rho=15 \mathrm{~mm}$ ). 


\section{ACKNOWLEDGEMENTS}

The authors of this work would like to express their gratitude to the Spanish Ministry of Economy and Competitiveness and to the European Regional Development Fund (ERDF) for financing the National Plan Project (Ref.: BIA2015-67479-R) under the name of "The Critical Distance in Rock Fracture".

\section{CONFLICT OF INTEREST}

The authors of this work declare that they have no conflict of interest.

\section{REFERENCES}

[1] Creager M, Paris C. Elastic field equations for blunt cracks with reference to stress corrosion cracking. Int. J. Fract. 1967;3:247-52.

[2] Glinka G, Newport A. Universal features of elastic notch tip stress fields. Int. J. Fatigue. 1987;9:143-50.

[3] Pluvinage G. Fatigue and fracture emanating from notch; the use of the notch stress intensity factor. Nucl. Eng. Des. 1998;185:173-84.

[4] Chen DH, Chen L. The admissible range of notch root radius for applying the singular stress field to its fracture analysis. Eng. Fract. Mech. 2018;202:202-13.

[5] $\mathrm{Wu} \mathrm{CD}$, Tsai HW. Effect of notch radius on nanocrystalline $\mathrm{Au}$ under tensile deformation at low temperature. J. Comput. Theor. Nanosci. 2017;14(10):4669-73.

[6] Rozumek D, Faszynka S. Influence of the notch radius on fatigue crack propagation in beam specimens of 2017A-T4 alloy. Mat. Sci. 2017;53(3):112-17.

[7] Aliha MRM, Ayatollahi MR, Smith DJ, Pavier MJ. Geometry and size effects on fracture trajectory in a limestone rock under mixed mode loading. Eng. Fract. Mech. 2010;77:2200-12.

[8] Aliha MRM, Hosseinpour GhR, Ayatollahi MR. Application of cracked triangular specimen subjected to three-point bending for investigating fracture behavior of rock materials. Rock Mech. Rock Eng. 2013;46:1023-34.

[9] Aliha MRM, Bahmani A, Akhondi Sh. Determination of mode III fracture toughness for different materials using a new designed test configuration. Mater. Design. 2015;86:863-871.

[10] Dehghany M, Saeidi Googarchin H, Aliha MRM. The role of first non-singular stress terms in mixed mode brittle fracture of V-notched components: an experimental study. Fatigue Fract. Eng. Mater. Struct. 2017;40:623-641.

[11] Aliha MRM, Madhavi E, Ayatollahi MR. The influence of specimen type on tensile fracture toughness of rock materials. Pure Appl. Geophys. 2017;174:1237-53. 
[12] Justo J, Castro J, Cicero S, Sánchez-Carro MA, Husillos R. Notch effect on the fracture of several rocks: Application of the Theory of the Critical Distances. Theor. Appl. Fract. Mech. 2017;90:251-258.

[13] Justo J, Castro J, Cicero S. Energy-based approach for fracture assessment of several rocks containing Ushaped notches through the application of the SED criterion. Int. J. Rock Mech. Min. Sci. 2018;110:306315.

[14] Gómez FJ, Elices M, Valiente A. Cracking in PMMA containing U-shaped notches. Fatigue Fract. Eng. Mater. Struct. 2000;23:795-803.

[15] Dugdale DS. Yielding of steel sheets containing slits. J. Mech. Phys. Solids. 1960;8:100-108.

[16] Barenblatt GI. The formation of equilibrium cracks during brittle fracture. General ideas and hypothesis. Axially symmetric cracks. J. Appl. Math. Mech. 1959;23:622-636.

[17] Gómez FJ, Elices M. A fracture criterion for blunted V-notched samples. Int. J. Fract. 2004;127:239-264.

[18] Carpinteri A, Cornetti P, Pugno N, Sapora A, Taylor D. A finite fracture mechanics approach to structures with sharp V-notches. Eng. Fract. Mech. 2008;75(7):1736-1752.

[19] Neuber H. Theory of notch stresses. Berlin: Springer-Verlag; 1958.

[20] Erdogan F, Sih CG. On the crack extension in plates under plane loading and transverse shear. J. Basic Eng. 1963;85:519-525.

[21] Lazzarin P, Zambardi R. A finite-volume-energy based approach to predict the static and fatigue behavior of components with sharp V-shaped notches. Int. J. Fract. 2001;112(3):275-298.

[22] Torabi AR, Berto F, Campagnolo A, Akbardoost J. Averaged strain energy density criterion to predict ductile failure of U-notched Al 6061-T6 plates under mixed mode loading. Theor. Appl. Fract. Mech. 2017;91:86-93.

[23] Taylor D. The theory of critical distances: a new perspective in fracture mechanics. London: Elsevier; 2007.

[24] Peterson RE. Notch sensitivity. New York: McGraw Hill; 1959.

[25] Susmel L, Taylor D. An elasto-plastic reformulation of the Theory of Critical Distances to estimate lifetime of notched components failing in the low/medium-cycle fatigue regime. J. Eng. Mater. Technol. Trans. 2010, ASME 132:0210021-0210028.

[26] Cornetti P, Sapora A, Carpinteri A. Short cracks and V-notches: finite fracture mechanics vs. cohesive crack model. Eng. Fract. Mech. 2016;168:2-12.

[27] Chang KJ. On the maximum strain criterion - a new approach to the angled crack problem. Eng. Fract. Mech. 1981;14:107-124.

[28] Hussain MA, Pu SL, Underwood J. Strain energy release rate for a crack under combined mode I and mode II, Fracture Analysis, ASTM STP 560. Philadelphia: ASTM; 1974. 
[29] Aliha MRM, Ashtari R, Ayatollahi MR. Mode I and mode II fracture toughness testing for a coarse grain marble. Appl. Mech. Mater.2006;5:181-188.

[30] Mirsayar MM, Razmi A, Aliha MRM, Berto F. EMTSN criterion for evaluating mixed mode $1 /$ II crack propagation in rock materials. Eng. Fract. Mech. 2018;190:186-197.

[31] Aliha MRM, Berto F, Mousavi A, Razavi SMJ. On the applicability of ASED criterion for predicting mixed mode I + II fracture toughness results of a rock material. Theor. Appl. Fract. Mech. 2017;92:198-204.

[32] Razavi SMJ, Aliha MRM, Berto F. Application of an average strain energy density criterion to obtain the mixed mode fracture load of granite rock tested with cracked asymmetric four-point bend specimens. Theor. Appl. Fract. Mech. 2018;97:419-425.

[33] Lataji EZ. Effect of tensile stress gradient on brittle fracture initiation. Int. J. Rock Mech. Min. Sci. Geomech. Abstr. 1972;9:569-78.

[34] Schwartzkopff AK, Melkoumian NS, Xu C. Fracture mechanics approximation to predict the breakdown pressure using the theory of the critical distances. Int. J. Rock Mech. Min. Sci. 2017;95:48-61.

[35] Mahanta B, Singh TN, Ranjith PG. Influence of thermal treatment on mode I fracture toughness of certain Indian rocks. Eng. Geol. 2016;210:103-14.

[36] Feng G, Kang Y, Meng T, Hu YQ, Li XH. The influence of temperature on Mode I fracture toughness and fracture characteristics of sandstone. Rock Mech. Rock. Eng. 2017;50:2007-19.

[37] Guo LL, Zhang YB, Zhang YJ, Yu ZW, Zhang JN. Experimental investigation of granite properties under different temperatures and pressures and numerical analysis of damage effect in enhanced geothermal system. Renew. Energ. 2018;126:107-25.

[38] Zhao Z. Thermal influence on mechanical properties of a granite: a microcracking perspective. Rock Mech. Rock Eng. 2016;49:747-62.

[39] Sirdesai NN, Singh TN, Ranjith PG, Singh R. Effect of varied durations of thermal treatment on the tensile strength of red sandstone. Rock Mech. Rock Eng. 2017;50:205-13.

[40] Meredith PG, Atkinson BK. Fracture toughness and subcritical crack growth during high-temperature tensile deformation of Westerly granite and Black gabbro. Phys. Earth Planet Inter. 1985;39(1):33-51.

[41] Al-Shayea N. Comparing reservoir and outcrop specimens for mixed mode I-II fracture toughness of a limestone rock formation at various conditions. Rock Mech. Rock Eng. 2002;34(4):271-297.

[42] Zuo JP, Xie HP, Dai F, Ju Y. Three-point bending test investigation of the fracture behaviour of siltstone after thermal treatment. Int. J. Rock Mech. Min. Sci. 2014;70(9):133-143.

[43] Dongming Z, Yushun Y. The effect of high temperature on tensile strength and damage characteristics of limestone. Geotech. Geol. Eng. 2018;36:3527-35.

[44] Schmidt RA. A microcrack model and its significance to hydraulic fracturing and fracture toughness testing. In: Proceedings of $21^{\text {st }}$ US symposium rock mechanics: 1980;581-90. 
[45] UNE 22950-2. Mechanical Properties of Rocks, Strength Determination Tests. Part 2: Tensile Strength, Indirect Determination (Brazilian Test). AENOR; 1990 [Spanish].

[46] ASTM D3967-16. Standard test method for splitting tensile strength of intact rock core specimens. ASTM International, West Conshohocken, PA; 2016.

[47] Amaral PM, Guerra Rosa L, Cruz Fernandes J. Assessment of fracture toughness in ornamental stones. Int. J. Rock Mech. Min. Sci. 2008;45:554-563.

[48] UNE-EN 13161. Natural stone test methods - Determination of flexural strength under constant moment. AENOR, 2008 [Spanish].

[49] CEN/TS 14425-1. Advanced Technical Ceramics - Test Methods for Determination of Fracture Toughness of Monolithic Ceramics - Part 1: Guide to Test Method Selection. European: Committee for Standarization; 2003.

[50] Srawley J, Gross B. Cracks and fracture. ASTM Spec. Tech. Publ. 1976;601:559-579.

[51] De Bresser JHP, Urai JL, Olgaard DL. Effect of water on the strength and microstructure of Carrara marble axially compressed at high temperature. J. Struct. Geol. 2005;27:265-281.

[52] Nara Y, Morimoto K, Yoneda T, Hiroyoshi N, Kaneko K. Effects of humidity and temperature on subcritical crack growth in sandstone. Int. J. Solids Struct. 2011;48:1130-40.

[53] Aliha MRM, Ayatollahi MR. Two-parameter fracture analysis of SCB rock specimen under mixed mode loading. Eng. Fract. Mech. 2013;103:115-23.

[54] Ayatollahi MR, Aliha MRM. On the use of Brazilian disc specimen for calculating mixed mode I-II fracture toughness of rock materials. Eng. Fract. Mech. 2008;75:4631-41. 